\title{
The CXCL12/CXCR4 chemokine ligand/receptor axis in cardiovascular disease
}

\author{
Yvonne Döring ${ }^{1}$, Lukas Pawig ${ }^{2}$, Christian Weber ${ }^{1,3,4 *+}$ and Heidi Noels ${ }^{2 * t}$ \\ 1 Institute for Cardiovascular Prevention (IPEK), Ludwig-Maximilians-University, Munich, Germany \\ 2 Institute for Molecular Cardiovascular Research, RWTH Aachen University, Aachen, Germany \\ ${ }^{3}$ German Centre for Cardiovascular Research (DZHK), Partner Site Munich Heart Alliance, Munich, Germany \\ ${ }^{4}$ Cardiovascular Research Institute Maastricht, University of Maastricht, Maastricht, Netherlands
}

\section{Edited by:}

Christian Albert Gleissner, University

of Heidelberg, Germany

Reviewed by:

Amalia Forte, Second University of Naples, Italy

Giuseppe Rengo, Salvatore Maugeri

Foundation, Italy

Jürgen Bernhagen, RWTH Aachen

University, Germany

${ }^{*}$ Correspondence:

Christian Weber, Institute for

Cardiovascular Prevention (IPEK),

Ludwig-Maximilians-University

Munich, Pettenkoferstraße 9, 80336

Munich, Germany

e-mail: christian.weber@

med.uni-muenchen.de

Heidi Noels, Institute for Molecular

Cardiovascular Research, RWTH

Aachen University, Pauwelsstrasse

30, 52074 Aachen, Germany

e-mail:hnoels@ukaachen.de

${ }^{\dagger}$ These authors have contributed

equally and share senior-authorship

to this work.
The chemokine receptor CXCR4 and its ligand CXCL12 play an important homeostatic function by mediating the homing of progenitor cells in the bone marrow and regulating their mobilization into peripheral tissues upon injury or stress. Although the CXCL12/CXCR4 interaction has long been regarded as a monogamous relation, the identification of the pro-inflammatory chemokine macrophage migration inhibitory factor (MIF) as an important second ligand for CXCR4, and of CXCR7 as an alternative receptor for CXCL12, has undermined this interpretation and has considerably complicated the understanding of CXCL12/CXCR4 signaling and associated biological functions. This review aims to provide insight into the current concept of the CXCL12/CXCR4 axis in myocardial infarction (MI) and its underlying pathologies such as atherosclerosis and injury-induced vascular restenosis. It will discuss main findings from in vitro studies, animal experiments and large-scale genome-wide association studies. The importance of the CXCL12/CXCR4 axis in progenitor cell homing and mobilization will be addressed, as will be the function of CXCR4 in different cell types involved in atherosclerosis. Finally, a potential translation of current knowledge on CXCR4 into future therapeutical application will be discussed.

Keywords: CXCR4, CXCL12, CXCR7, MIF, cardiovascular disease, atherosclerosis, restenosis, myocardial infarction

\section{INTRODUCTION}

Chemokines are small $8-12 \mathrm{kDa}$ cytokines that mediate cell chemotaxis and arrest by binding to their respective receptors on the cell surface (Blanchet et al., 2012) (Box 1). The chemokine receptor CXCR4 and its ligand CXCL12, also known as stromal cell-derived factor 1 (SDF-1), are attractive therapeutic targets in the treatment of cancer, as they support migration, proliferation, and survival of cancer cells (Teicher and Fricker, 2010; Domanska et al., 2013). Also, CXCR4 is intensively studied in different autoimmune diseases, including rheumatoid arthritis, systemic lupus erythematosus, and autoimmune disorders of the central nerve system as multiple sclerosis, for its involvement in leukocyte chemotaxis in specific inflammatory conditions (Debnath et al., 2013; Domanska et al., 2013). Furthermore, the CXCL12/CXCR4 axis plays a crucial role in the homing of stem and progenitor cells in the bone marrow and controls their mobilization into peripheral blood and tissues in homeostatic conditions as well as after tissue injury or stress. Small molecule CXCR4 inhibitors are intensively being studied as mobilizers of hematopoietic stem cells for transplantation therapy of patients with specific types of cancer (Debnath et al., 2013) (Box 2). Upregulation of CXCL12 in hypoxic conditions with subsequent mobilization of CXCR4-positive stem and progenitor cells (Ceradini et al., 2004) has prompted researchers to explore the role and therapeutic value of progenitor cells and the CXCL12/CXCR4 axis in diverse models of ischemic injury, including in heart, kidney, lung, and brain. In addition, CXCL12/CXCR4-mediated mobilization of progenitor cells has also been intensively investigated in models of vascular injury-induced restenosis as observed after e.g., organ transplantation, balloon angioplasty, or stent implantation (Schober et al., 2006), as will be discussed in more detail later. Also, CXCR4 acts as an important coreceptor for human immunodeficiency virus (HIV) facilitating its entry in host CD $4^{+}$ T-cells. In fact, the low-molecular weight CXCR4 antagonist AMD3100, the prototype of a group of so-called bicyclams, was originally identified in 1994 as a highly potent inhibitor of HIV replication in human T-cells. Only 3 years later, it was unraveled that blockade of CXCR4 was the underlying mechanism of the HIV inhibitory function of AMD3100 (De Clercq, 2000; Debnath et al., 2013). Taken together, it is not surprising that the CXCL12/CXCR4 axis is one of the most studied chemokine ligand/receptor axes in a diversity of pathological disorders.

Here we will focus on the role of CXCR4 in coronary artery disease (CAD) (Box 3). This pathology is caused by atherosclerosis, 


\section{Box 1 | Chemokines.}

Chemokines constitute the largest family of cytokines and are defined as small molecules that trigger chemotaxis of cells along a concentration gradient. They are generally important in cell signaling (Bachelerie et al., 2014). Although chemokines are a large family, they all have the same basic structure, known as the chemokine fold, which consists of a short N-terminal region, an extended N-loop region, followed by three $\beta$-strands and one $\alpha$-helix (Rajagopalan and Rajarathnam, 2006). To date, chemokines have been classified into four major subdivisions, being C-, CXC-, CC-, and CX3C-chemokines. This classification is based on the number and spacing of conserved N-terminal cysteine groups, which form disulfide bonds and are hence crucial for the spatial arrangement and stability of the chemokine (Rajagopalan and Rajarathnam, 2006). In addition to these classical chemokine groups, chemokine-like function (CLF) chemokines have recently been suggested to form a fifth subclass, which does not have the classical chemokine fold and N-terminal residues, but nevertheless exerts typical chemokine activities (Tillmann et al., 2013).

The chemokine receptors are classified according to the chemokines they bind and are divided into two groups, being G-proteincoupled receptors (GPCRs) and atypical chemokine receptors. GPCRs generally signal by activating G-proteins, leading to a plethora of cellular functions, whereas atypical chemokine receptors appear to shape chemokine gradients and scavenge chemokines in the context of inflammation independent of G-protein signaling (Bachelerie et al., 2014). Apart from the classical function of cell recruitment, chemokines also mediate arrest of rolling leukocytes through activation of integrins. Some chemokines, like CXCL12, also have a role in cell homeostasis, which together with chemotaxis and arrest is an important regulatory factor of atherogenesis, as discussed in detail recently (Zernecke and Weber, 2014).

\section{Box 2 | CXCR4 Antagonists.}

AMD3100, also known as Plerixafor or Mozobil (Genzyme Corp), is the first CXCR4 antagonist that has been approved by the FDA as mobilizer of hematopoietic stem cells in combination with G-CSF in treatment of patients with non-Hodgkin's lymphoma and multiple myeloma, and many other small molecule inhibitors of CXCR4 are under investigation or in clinical trial for different pathological settings, as recently discussed in detail (Debnath et al., 2013). AMD3100 is the prototype of bis-tetraazamacrocycles (bicyclams), a class of highly potent HIV1 antagonists. Subsequent studies examining the effect of structural modifications of AMD3100 on pharmacokinetic properties led to the discovery of AMD3465, a monocyclam analog of AMD3100, in which the second cyclam ring of AMD3100 was substituted by a pyridinylmethylene group. Similarly as AMD3100, AMD3465 interferes with the binding of CXCL12 to CXCR4, thereby preventing CXCL12 to trigger CXCR4 endocytosis and CXCR4-induced intracellular signaling as calcium mobilization and MAPK activation. As an advantage, AMD3465 shows a 10-fold higher effectiveness in inhibiting CXCR4 activity compared to AMD3100, but has no FDA approval to date and hence is less used in studies (Hatse et al., 2005).

\section{Box 3 | Cardiovascular Disease.}

Cardiovascular disease, including ischemic stroke and heart attack, is a leading cause of death and morbidity worldwide. Its underlying pathology, atherosclerosis, is defined as a chronic inflammatory disease of arterial walls (Hansson and Hermansson, 2011; Weber and Noels, 2011). Atherosclerotic lesion formation is initiated by dysfunction of the endothelial layer lining the arterial wall, caused by irritative stimuli such as dyslipidemia. Upon endothelial activation, monocytes start adhering to and migrating through the endothelium. Monocytederived macrophages in the arterial wall take up cholesterol-rich LDL particles, leading to the formation of so-called foam cells. As the atherosclerotic lesion progresses, smooth muscle cells (SMCs) migrate from the media to the intima, resident intimal SMCs proliferate and extracellular matrix molecules such as elastin, collagen and proteoglycans are synthesized. A necrotic core made of extracellular lipids derived from necrotic and apoptotic foam cells forms in advanced plaques, along with a fibrous cap consisting of collagen and SMCs. The ultimate complications of atherosclerosis are flow-limiting stenosis and plaque rupture, the latter triggering vessel occlusion through thrombus formation.

a chronic inflammatory disease of the vessel wall characterized by the development of lesions through continuous and progressive infiltration and accumulation of lipids and leukocytes (Hansson and Hermansson, 2011; Weber and Noels, 2011). Restriction of the blood flow by extensive lesions or thrombus formation caused by rupture of unstable plaques is a main cause for myocardial ischemia and infarction. Interventions such as balloon angioplasty or stent implantation aim to re-open the occluded artery, but are often associated with a re-narrowing of the vessel lumen (restenosis) caused by injury-induced vascular remodeling and neointimal hyperplasia. Bypass grafting remains the gold standard therapy for severe, diffuse coronary artery occlusion, particularly in the elderly and patients with diabetes. In this context vein graft failure is a major problem and late vein graft failure is associated with neointimal hyperplasia and accelerated atherosclerosis. Interestingly, recent genome-wide association studies (GWAS) revealed CXCL12 as an important candidate gene associated with CAD and myocardial infarction (MI), but the underlying mechanisms remain totally unclear (Burton et al., 2007; Samani et al., 2007; Kathiresan et al., 2009; Farouk et al., 2010; Schunkert et al., 2011) (Box 4).

To facilitate future research exploring the role of CXCL12 and CXCR4 in CAD, this review aims to discuss the current concept of the CXCL12/CXCR4 axis in atherosclerosis, injury-induced vascular restenosis and $\mathrm{MI}$ in relation to its role in progenitor cell mobilization and biological functions in atherosclerosis-relevant cell types. We will also introduce MIF as an alternative chemokine ligand for CXCR4, and CXCR7 as an additional receptor for 
CXCL12, to emphasize the complexity of identifying specific CXCL12- and CXCR4-associated functions through intertwining of chemokine (receptor) signaling.

\section{CXCR4 AS A CHEMOKINE RECEPTOR FOR CXCL12 AND MIF CXCR4 AND ITS CHEMOKINE LIGAND CXCL12}

The chemokine receptor CXCR4 belongs to the family of sevenspan transmembrane G-protein-coupled chemokine receptors (GPCRs). It is ubiquitously expressed and evolutionary conserved, with $89 \%$ of similarity between the human and mouse protein. In 1996 SDF-1, later called CXCL12, was identified as a ligand for CXCR4 (Bleul et al., 1996a; Oberlin et al., 1996). Similar as CXCR4, CXCL12 is highly conserved, with human and mouse showing around $92 \%$ amino acid (aa) identity for both ubiquitously expressed isoforms $\alpha$ ( $89 \mathrm{aa}$ ) and $\beta$ (93 aa) (Shirozu et al., 1995). Except for these 2 classical isoforms, which are so far functionally indistinguishable and differ only in 4 amino acids at the C-terminal end, four additional isoforms have been identified in humans. These $\gamma$ (119 aa), $\delta$ (140 aa), $\varepsilon$ (90 aa), and $\phi(100 \mathrm{aa})$ isoforms show a more restricted expression pattern and have been much less studied. They result from differential splicing and only differ at their C-terminal region (Yu et al., 2006) (Figure 1).

Mice deficient for Cxcl12 or Cxcr4 die perinatally due to defects in hematopoiesis, vasculo-, cardio-, and neurogenesis (Nagasawa et al., 1996; Ma et al., 1998; Tachibana et al., 1998; Zou et al.,
1998; Ara et al., 2005). The importance of the CXCL12/CXCR4 axis in embryonic development is associated with an essential role in homeostatic (progenitor) cell migration. This clarifies the classification of the CXCL12/CXCR4 axis into the "homeostatic/constitutive" chemokine ligand/receptor group, instead of the "inflammatory/inducible" group of chemokines, which groups chemokines that are upregulated during inflammation to drive immune responses (Bachelerie et al., 2014). The CXCR4 receptor and its ligand CXCL12 are mostly studied for their crucial role in the homing of (hematopoietic) progenitor cells in the bone marrow and their mobilization into the periphery in physiological and pathological conditions. Furthermore, the CXCL12/CXCR4 axis is involved in chemotaxis, cell arrest, angiogenesis, and cell survival. These functions explain not only the interest of oncologists in CXCR4, but also underlie the involvement of the CXCL12/CXCR4 axis in CAD, as will be discussed in more detail later.

Binding of CXCL12 to CXCR4 mediates intracellular signaling through a classical heterotrimeric G-protein, composed of an $\mathrm{G} \alpha, \mathrm{G} \beta$, and $\mathrm{G} \gamma$ subunit. Of the 4 general classes of $\mathrm{G} \alpha$ proteins, named $\mathrm{G} \alpha_{\mathrm{s}}, \mathrm{G} \alpha_{\mathrm{i}}, \mathrm{G} \alpha_{\mathrm{q}}$, and $\mathrm{G} \alpha_{12}$, CXCR4 signaling seems mainly coupled to the $\mathrm{G} \alpha_{\mathrm{i}}$ subunit. Receptor stimulation induces the dissociation of the heterotrimeric G-protein. The $\mathrm{G} \alpha_{\mathrm{i}}$ monomer inhibits adenylyl cyclase activity and triggers MAPK and PI3K pathway activation, whereas the G $\beta \gamma$ dimer triggers

\section{Box 4 | Genome-wide Association Studies.}

Genome-wide association studies (GWAS) have emerged as a very powerful tool in medical research over the last decade. In association studies, the frequency of alleles or genotype-variants is compared between disease cases and controls. GWAS apply this principle to the whole genome, i.e., a dense set of single nucleotide polymorphisms (SNPs) across the whole genome is genotyped to find out the most common variation of SNP patterns in a disease of interest (Hirschhorn and Daly, 2005). This method is a comprehensive, unbiased approach to identify genes which are regulated in a disease of interest.

Since CAD is a multifactorial disease, it is a highly interesting target for GWAS. Indeed, several GWAS in the context of CAD have been performed over the last years by the Wellcome Trust Case Control Consortium, the Ottawa Heart study, the Myocardial Infarction Genetics Consortium and others (Schunkert et al., 2011; Maouche and Schunkert, 2012). The first locus that was identified and could be replicated in all CAD-related GWAS was a strong signal on chromosome 9p21 (Farouk et al., 2010). Another strong locus that has sparked particular interest is on chromosome 10q11, close to the gene encoding CXCL12 (Farouk et al., 2010).

\begin{tabular}{|l}
\hline All \\
SDF-1 $\alpha$ K I I
\end{tabular}


intracellular calcium mobilization through the activation of phospholipase C (Teicher and Fricker, 2010). Furthermore, CXCL12 induces the recruitment of $\beta$-arrestin to CXCR4. This mediates receptor desensitization through CXCR4 endocytosis (Orsini et al., 1999), but also reduces CXCR4 coupling to $\mathrm{G} \alpha_{i}$ signaling, favoring $\beta$-arrestin-mediated MAPK activation. The latter was particularly shown upon overexpression-induced dimerization of CXCR4 with CXCR7, a chemokine receptor that will be discussed in more detail below (Decaillot et al., 2011) (Figure 2). Preferential signaling through $\mathrm{G}$-proteins vs. $\beta$-arrestin is not only influenced through dimer formation of CXCR4 with CXCR7, but also by the oligomerization state of CXCL12 (Drury et al., 2011; Ray et al., 2012).

\section{MIF AS AN ALTERNATIVE CHEMOKINE LIGAND FOR CXCR4}

The CXCL12/CXCR4 axis was long considered a monogamous relation, until in 2007 the chemokine MIF was surprisingly identified as an alternative ligand for CXCR4 (Bernhagen et al., 2007). MIF is a ubiquitously expressed and highly conserved protein of 114 aa (excluding the N-terminal methionine which is posttranslationally removed), with $90 \%$ homology between human and mouse (Bernhagen et al., 1994). MIF plays an important role in cell recruitment and arrest through binding to the chemokine receptors CXCR2 and CXCR4 (Bernhagen et al., 2007). However, it cannot be classified into one of the four typical chemokine classes $\left(\mathrm{C}, \mathrm{CC}, \mathrm{CXC}, \mathrm{CX}_{3} \mathrm{C}\right)$ due to the absence of a characteristic cysteine motif in its $\mathrm{N}$-terminus, and is therefore called a chemokine-like function chemokine (Box 1). In contrast to CXCL12, MIF is secreted in response to diverse inflammatory stimuli, and has been associated with a clear pro-inflammatory and pro-atherogenic role in multiple studies of patients and animal models (Pan et al., 2004; Bernhagen et al., 2007). On the other hand, MIF can also exert protective functions, as observed after myocardial ischemia/reperfusion injury (MI/IRI) and in experimental liver fibrosis. We will address the double-edged role of MIF in myocardial ischemia below. For the involvement of MIF in chronic atherosclerosis and injury-induced restenosis, we refer to a recent review by Tillmann et al. (2013).

\section{CXCR7, AN ALTERNATIVE RECEPTOR FOR CXCL12 HETERODIMERIZING WITH CXCR4}

In 2005, CXCL12 was revealed to bind a second chemokine receptor, named CXCR7 (or RDC1), with an even 10-fold higher affinity compared with CXCR4 (Balabanian et al., 2005; Burns et al., 2006). Similarly as CXCR4, CXCR7 is highly conserved between human and mouse. Its deletion in mice is perinatally lethal and associated with defective cardiovascular development (Sierro et al., 2007; Yu et al., 2011b). CXCR7 has been

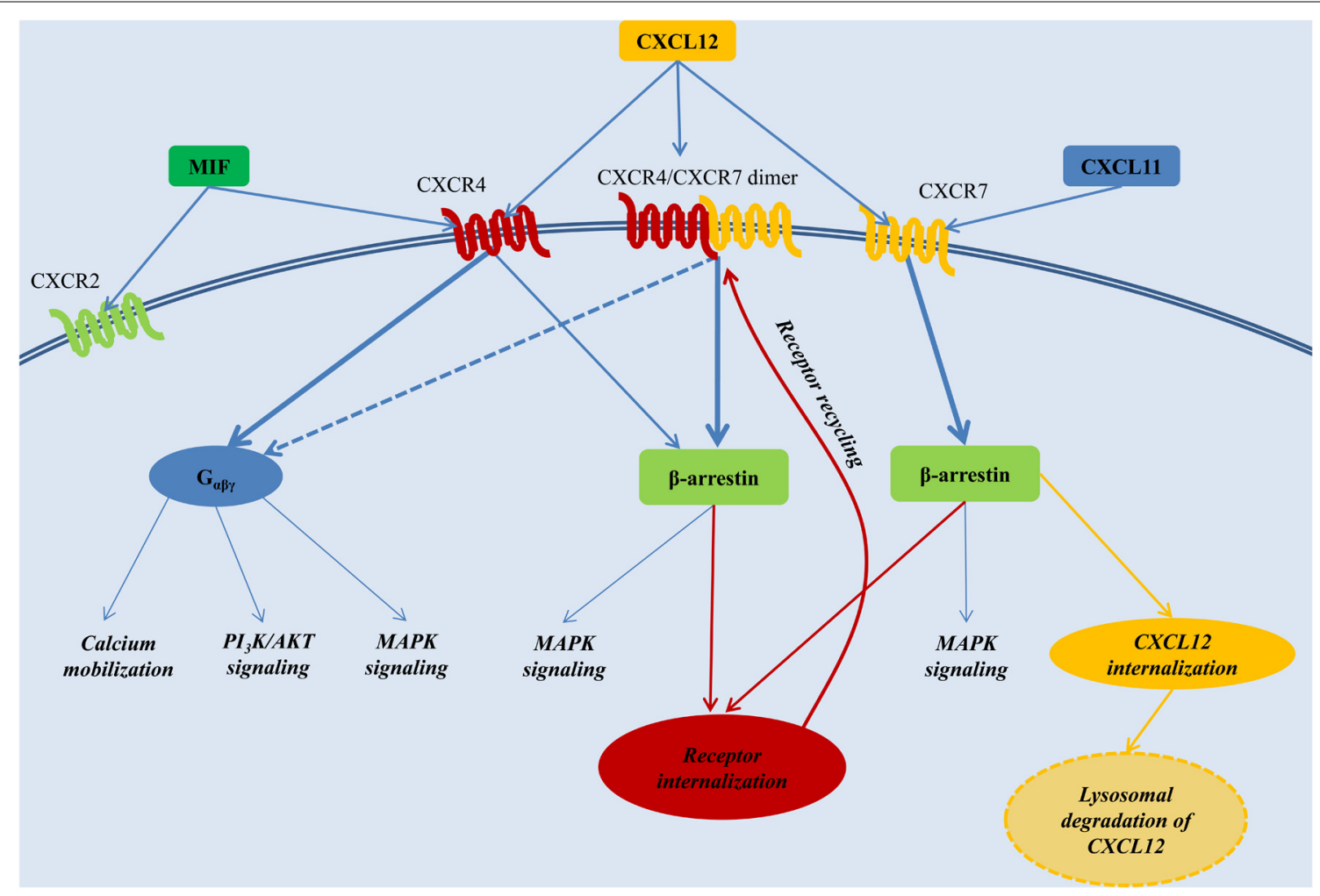

FIGURE 2 | The CXCL12 signaling network. CXCL12 employs two distinct receptors, CXCR4 and CXCR7. CXCR4 additionally acts a receptor for MIF, whereas CXCR7 can also bind CXCL11. Generally, stimulation of CXCR4 triggers preferentially G-protein-coupled signaling, whereas activation of CXCR7 or the CXCR4/CXCR7 complex induces $\beta$-arrestin-mediated signaling. Internalization of the receptors CXCR4 and CXCR7, and subsequent recycling to the cell membrane, is also mediated through $\beta$-arrestin. Upon binding to CXCR7, CXCL12 is internalized and subjected to lysosomal degradation. AKT, PKB, Protein kinase B; MAPK, mitogen-activated protein kinase; MIF, macrophage migration inhibitory factor; PI3K, phosphatidylinositide 3-kinase; $\mathrm{G}_{\alpha \beta \gamma}$, heterotrimeric G-protein consisting of the subunits $\alpha, \beta$, and $\gamma$. 
implicated in cell survival and adhesion (Burns et al., 2006) and can mediate CXCL12-directed T-cell chemotaxis independently from CXCR4 (Balabanian et al., 2005; Kumar et al., 2012). Binding of the chemokine ligands CXCL12 and CXCL11 (also called I-TAC) to CXCR7 enhances continuous CXCR7 internalization and delivery of the chemokine ligands to the lysosomes for degradation (Luker et al., 2010; Naumann et al,, 2010). Such CXCR7-mediated regulation of available CXCL12 concentrations has associated CXCR7 with a function as decoy receptor, reducing acute CXCL12/CXCR4 signaling (Luker et al., 2010). Furthermore, study of a CXCR7 agonist recently suggested downregulation of CXCR4 protein levels by CXCR7 signaling as another negative regulatory mechanism of CXCR7 toward the CXCL12/CXCR4 axis (Uto-Konomi et al., 2013). Also, heterodimerization of CXCR7 with CXCR4 interferes with CXCR4-induced $G \alpha_{i}$ protein-mediated signaling and favors $\beta$ arrestin-linked signaling (Levoye et al., 2009; Decaillot et al., 2011). On the other hand, the CXCL12 scavenging function of CXCR7 can also positively influence CXCR4-mediated migration by preventing the downregulation of CXCR4 surface expression and function through excessive CXCL12 concentrations (Sanchez-Alcaniz et al., 2011). In addition to its modulatory effect on CXCL12/CXCR4 signaling, CXCR7 is able to mediate CXCL12-induced MAPK activation independently from CXCR4 (Wang et al., 2011). Although the precise signaling mechanisms downstream of CXCR7 remain unclear, CXCR7 does not bind to or induce the activation of heterotrimeric G-proteins as typical in classical GPCR signaling, but depends on ligand-induced $\beta$-arrestin recruitment (Rajagopal et al., 2010) (Figure 2). This atypical signaling explains why CXCR7 was recently renamed atypical chemokine receptor (ACKR) 3 (Bachelerie et al., 2014).

As an important consideration, the widely used CXCR4 antagonist AMD3100 (Box 2) was recently revealed to be an allosteric agonist of CXCR7, being able to induce the recruitment of $\beta$-arrestin to CXCR7 at concentrations from $10 \mu \mathrm{M}$. Also, AMD3100 increased CXCL12 binding and CXCL12-triggered $\beta$ arrestin recruitment to CXCR7 (Kalatskaya et al., 2009). The CXCR4 antagonist TC14012 even showed a higher agonistic effect on CXCR7 (Gravel et al., 2010). These findings, together with the regulatory effects of CXCR7 on CXCL12/CXCR4 signaling, considerably complicate the interpretation of all studies aiming to dissect the molecular mechanisms and biological consequences of specifically CXCL12/CXCR4 signaling.

\section{THE CXCL12/CXCR4 AXIS MEDIATES HOMING AND MOBILIZATION OF PROGENITOR CELLS HOMING OF PROGENITOR CELLS IN THE BONE MARROW}

In physiological conditions low numbers of hematopoietic stem and progenitor cells (HSPCs) constantly circulate from the bone marrow to the blood and back. The CXCL12/CXCR4 axis has been shown to play a crucial role in the homing and retention of HSPCs in the stem cell niches of the bone marrow (Mazo et al., 2011). First, CXCL12 secreted by endothelial cells of sinusoids in the bone marrow may trigger firm arrest of rolling CXCR4 $^{+}$HSPCs through CXCR4-mediated integrin activation (Peled et al., 2000; Mazo et al., 2011). After vascular extravasation, HSPCs home into specialized bone marrow niches that provide optimal conditions for HSPC survival, self-renewal, and lineage differentiation and function (Jones and Wagers, 2008). High expression of CXCL12 by bone marrow stromal cells constitutes an important adhesive mechanism to retain CXCR4 ${ }^{+}$ HSPCs in the bone marrow.

\section{STRESS-INDUCED MOBILIZATION OF PROGENITOR CELLS}

In conditions of stress or injury, HSPCs lose their anchorage in these niches and are increasingly mobilized into the circulation (Mazo et al., 2011). Interference with CXCL12/CXCR4-mediated retention is an important mechanism underlying HSPC mobilization. For example, granulocyte colony-stimulating factor (G-CSF or CSF3), a mobilizing cytokine frequently used in the clinic, reduces CXCL12 expression by bone marrow osteoblasts through depletion of endosteal macrophages that support osteoblast function (Semerad et al., 2005; Winkler et al., 2010). Furthermore, GCSF has been associated with proteolytic inactivation of CXCR4 on HSPCs in the bone marrow (Levesque et al., 2003), despite enhanced surface expression of CXCR4 on bone marrow cells upon G-CSF treatment (Petit et al., 2002). In addition, GCSF-induced mobilization of HSPCs involves activity of the protease dipeptidyl-peptidase 4 (DPP4, also known as CD26), which inactivates CXCL12 through proteolysis (Christopherson et al., 2003a,b; Campbell and Broxmeyer, 2008). A similar role in CXCL12 destabilization during HSPC mobilization has been suggested for the proteases matrix metallopeptidase (MMP) 9, neutrophil elastase and cathepsin G. But although these proteases are upregulated in the bone marrow upon treatment with G-CSF (Levesque et al., 2002), combined inhibition of a broad range of metalloproteinases and neutrophil serine proteases_-including MMP9, neutrophil elastase and cathepsin G-did not significantly affect G-CSF-triggered HSPC mobilization (Levesque et al., 2004).

A fourth mechanism proposed to interfere with CXCL12/CXCR4-mediated retention of HSPCs in the bone marrow is an increased plasma level of CXCL12, which may favor CXCL12-induced migration of HSPCs into the circulation over their retention in the bone marrow. For example, increased concentrations of CXCL12 in the blood due to injection of CXCL12-expressing adenovirus or stabilized methionineCXCL12 induced the mobilization of hematopoietic cells and progenitors (Hattori et al., 2001; Moore et al., 2001). However, it has been debated whether this is indeed due to CXCL12-induced mobilization, or rather to a reduced CXCL12/CXCR4-mediated retention of these cells in the bone marrow caused by CXCL12induced downregulation of CXCR4 on their cell surface (Bonig and Papayannopoulou, 2012). Similarly, it is still debated whether the mobilization of HSPCs by CXCR4 antagonists, as was recently discussed in detail (Rettig et al., 2012), is mostly the result of a direct blockade of CXCR4 on HSPCs in the bone marrow interfering with CXCR4-mediated homing (Karpova et al., 2013), or whether these antagonists may also mediate HSPC egress by altering the CXCL12 gradient in favor of mobilization. In context of the latter, it was shown that treatment with the CXCR4 antagonist AMD3100 induces a fast release of CXCL12 from bone marrow stroma to the circulation, which may favor CXCL12/CXCR4-mediated mobilization of HSPCs 
into circulation over their anchorage in bone marrow niches (Dar et al., 2011).

Clearly, the CXCL12/CXCR4 axis plays a pivotal but complex role in the homing and mobilization of progenitor cells, and an intertwinement with different other pathways even further complicates the picture. For example, AMD3100-induced progenitor cell mobilization was recently shown to require the expression of MMP9 and endothelial nitric oxide synthase (eNOS, also known as NOS3) in bone marrow-derived cells (Jujo et al., 2010, 2013). Also, CXCL12-mediated homing and mobilization of progenitor cells is modulated by e.g., fms-related tyrosine kinase 3 (FLT3) ligand (Fukuda et al., 2005), transforming growth factor (TGF) $\beta$ (Basu and Broxmeyer, 2005), and CCR5 chemokine receptor ligands (Basu and Broxmeyer, 2009).

\section{SURVIVAL AND PROLIFERATION OF PROGENITOR CELLS}

In addition to homing and mobilization, the CXCL12/CXCR4 axis provides important survival and proliferative signals to progenitor cells (Lataillade et al., 2000; Lee et al., 2002; Broxmeyer et al., 2003a,b; Guo et al., 2005). Together, these functions underlie to a considerable extent the currently known involvement of the CXCL12/CXCR4 axis in CAD, as will be discussed in detail below.

\section{THE CXCL12/CXCR4 AXIS IN CAD: IDENTIFYING POTENTIAL FUNCTIONS AND UNDERLYING MECHANISMS FROM IN VITRO, ANIMAL AND PATIENT OBSERVATIONS}

The involvement of CXCR4 and its ligand CXCL12 in injuryinduced restenosis and MI has mostly been linked to progenitor cell recruitment. In contrast, the role of the CXCL12/CXCR4 axis in native atherosclerosis remains largely unclear, with mostly only in vitro studies shedding some light on the effect of CXCR4 signaling on cell type-specific functions relevant in atherogenesis. Here, we aim to provide an overview of in vitro, animal and patient observations that may provide insight into the (cell type-specific) effects of CXCR4 signaling on native atherosclerosis, injury-induced restenosis and MI (Table 1, Supplemental Table 1).

\section{CXCR4 IN MYOCARDIAL ISCHEMIA}

Protective effects through cardiomyocyte protection and progenitor cell recruitment

CXCR4 and its ligand CXCL12 are expressed in cardiac myocytes and fibroblasts, and myocardial ischemia significantly upregulates CXCL12 (Pillarisetti and Gupta, 2001; Yamani et al., 2005; Hu et al., 2007). Different studies have revealed a protective role for CXCL12/CXCR4 signaling after MI and MI/IRI through survival effects on resident cardiomyocytes and recruitment of protective circulating cells. Intracardiac or intramyocardial injection of CXCL12 reduced infarction size and increased cardiac function after MI/IRI (Hu et al., 2007) and MI (Segers et al., 2007; Saxena et al., 2008), and cardioprotective effects were blocked with AMD3100 (Hu et al., 2007). CXCL12-induced cardioprotection was associated with improved survival of hypoxic myocardium and increased neo-angiogenesis, and was linked with anti-apoptotic AKT (also known as $\mathrm{PKB}=$ protein kinase B) and MAPK3/1 (also known as ERK1/2) signaling in cardiac
Table 1 | The CXCL12/CXCR4 axis in CAD.

\section{CXCL12/CXCR4 IN MYOCARDIAL ISCHEMIA}

Expression

CXCL12 and CXCR4 expressed in cardiac

myocytes, fibroblasts and cardiac ECs

Myocardial ischemia increases CXCL12

expression

Hu et al., 2007; Saxena et al., 2008

Pillarisetti and Gupta, 2001;

Yamani et al., 2005; Hu et al., 2007

\section{Cardioprotective effects of CXCL12/CXCR4 signaling}

Reduced infarction size and increased Hu et al., 2007; Segers et al., cardiac function upon CXCL12 delivery 2007; Saxena et al., 2008

after $\mathrm{MI} / \mathrm{IRI}$ and $\mathrm{MI}$

Associated with:

Increased survival of cardiomyocytes

Increased neo-angiogenesis in

infarcted region

Enhanced incorporation of progenitor

cells in infarcted region

Hu et al., 2007; Saxena et al., 2008

Saxena et al., 2008

Abbott et al., 2004;

Elmadbouh et al., 2007;

Segers et al., 2007; Purcell

et al., 2012

Cardioprotective signaling through AKT

and ERK

Hu et al., 2007; Saxena et al., 2008

Enhanced VEGF expression

Saxena et al., 2008

\section{Cardiovascular detrimental effects of CXCR4 signaling}

Inflammatory cell infiltration

Chen et al., 2010a; Liehn

et al., 2011

Enhanced TNF $\alpha$ expression and

Chen et al., 2010a

cardiomyocyte apoptosis

\section{Contrasting effects of CXCR4 antagonist AMD3100}

Single treatment: cardioprotective after Jujo et al., 2010, 2013

$\mathrm{MI} / \mathrm{IRI}$ and $\mathrm{MI}$

Enhanced incorporation of progenitor

cells in infarcted region

Increased neo-vascularization

Daily treatment: cardioprotective after MI

Continuous administration: reduced

cardiac function and survival after $\mathrm{MI}$

Reduced incorporation of progenitor cells in the infarcted region despite

enhanced mobilization

Increased proliferation of resident

cardiac progenitor cells ( $\Rightarrow$ reduced

differentiation?)

\section{CXCL12/CXCR4 IN INJURY-INDUCED RESTENOSIS (WIRE INJURY} OF CAROTID ARTERY)

\section{Expression}

Vascular injury increases CXCL12 expression in plasma and vascular wall

Schober et al., 2003; Yin et al., 2010

Injury-induced CXCL12 upregulation in the vascular wall is mediated through:

HIF1 $\alpha$ upregulation

Karshovska et al., 2007

Apoptosis in injured artery
Proulx et al., 2007

Dai et al., 2010; Jujo et al. 2010

Jujo et al., 2010

Dai et al., 2010 


\section{Table 1 | Continued}

\begin{tabular}{|c|c|}
\hline \multicolumn{2}{|c|}{ Detrimental effects of CXCL12/CXCR4 signaling } \\
\hline $\begin{array}{l}\text { Apoe }{ }^{-/-} \text {treated with CXCL12 blocking } \\
\text { antibody }\end{array}$ & $\begin{array}{l}\text { Schober et al., 2003; } \\
\text { Zernecke et al., } 2005\end{array}$ \\
\hline \multicolumn{2}{|l|}{ Reduced neointimal lesion size } \\
\hline \multicolumn{2}{|l|}{$\begin{array}{l}\text { Reduced SMC content and reduced } \\
\text { mobilization of } \mathrm{Lin}^{-} \mathrm{Sca} 1^{+} \text {cells }\end{array}$} \\
\hline $\begin{array}{l}\text { Apoe }{ }^{-/-} \text {transplanted with } \mathrm{CxCr} 4^{-/-} \\
\text {bone marrow or treated locally with } \\
\text { lentivirus expressing mutant CXCL12 } \\
\text { (antagonist) }\end{array}$ & Zernecke et al., 2005 \\
\hline \multicolumn{2}{|l|}{ Reduced neointimal lesion size } \\
\hline \multicolumn{2}{|l|}{ Reduced SMC content } \\
\hline \multicolumn{2}{|l|}{ No effect on reendothelialization } \\
\hline $\begin{array}{l}\text { Apoe }{ }^{-/-} \text {treated with CXCR4 antagonist } \\
\text { AMD3465 }\end{array}$ & Karshovska et al., 2008 \\
\hline \multicolumn{2}{|l|}{ Reduced neointimal lesion size } \\
\hline \multicolumn{2}{|l|}{$\begin{array}{l}\text { Reduced SMC content and } \\
\text { mobilization of } \mathrm{Lin}^{-} \mathrm{Sca} 1^{+} \text {cells }\end{array}$} \\
\hline \multicolumn{2}{|l|}{ Reduced neointimal proliferation } \\
\hline \multicolumn{2}{|l|}{ No effect on reendothelialization } \\
\hline $\begin{array}{l}\text { Apoe }{ }^{-/-} \text {treated with CXCR4 antagonist } \\
\text { POL5551 }\end{array}$ & Hamesch et al., 2012 \\
\hline \multicolumn{2}{|l|}{ Reduced neointimal lesion size } \\
\hline \multicolumn{2}{|l|}{$\begin{array}{l}\text { Reduced SMC content and } \\
\text { mobilization of } \text { Lin }^{-} \text {Sca } 1^{+} \text {cells }\end{array}$} \\
\hline $\begin{array}{l}\text { Variable effect on macrophage content } \\
\text { and reendothelialization depending on } \\
\text { treatment regime }\end{array}$ & \\
\hline
\end{tabular}

\section{Protective effects of CXCL12/CXCR4 signaling}

Apoe $^{-/-}$injected with EPCs

Hristov et al., 2007

Blocking CXCR2 or CXCR4 on EPCs reduced adhesion to injured artery

\section{C57BL/6 injected with EPCs}

Yin et al., 2010

Enhanced reendothelialization and reduced neointimal lesion size with wild-type but not CXCR4-blocked EPCs C57BL/6 treated with Cxcl12 blocking antibody

Reduced mobilization of EPCs

(Sca $1^{+}$Flk $1^{+}$cells)

Reduced reendothelialization

No effect on neointimal lesion size

C57BL/6 injected with Foxc2-transgenic EPCs

Prior CXCR4 blockade on EPCs reduced their adhesion to the injured artery and reduced their protective effect on neointimal lesion size $\mathrm{NRMI}^{\mathrm{nu} / \mathrm{nu}}$ athymic nude mice injected with CXCR4-transgenic EPCs

Enhanced reendothelialization compared to infusion of wild-type EPCs

Yin et al., 2010

Li et al., 2011

Chen et al., 2010b

\section{Table 1 | Continued}

\section{CXCL12/CXCR4 IN CHRONIC ATHEROSCLEROSIS}

\section{Protective effects of CXCL12/CXCR4 signaling}

$A_{p o e^{-/-}}$treated with endothelial

Zernecke et al., 2009

apoptotic bodies (high-fat diet study)

Reduced lesion size, macrophage

content and apoptosis

Effect of apoptotic bodies reversed

upon treatment with AMD3100

\section{Possible detrimental effects of CXCL12/CXCR4 signaling}

Apoe $^{-/-}$with established

De Gaetano et al., 2013

atherosclerosis, treated with conjugated

linoleic acid (CLA)

CLA induced lesion regression

Associated with reduced CXCR4

expression and CXCL12-induced

chemotaxis of monocytes

Apoe ${ }^{-/-}$treated with $\mathrm{H}_{2} \mathrm{~S}$ donor

GYY4137

Reduced lesion size

Associated with reduced CXCR4

expression on macrophages

\section{Studies without effects of CXCL12/CXCR4 signaling}

Apoe $^{-/-}$treated with CXCL12

Bernhagen et al., 2007

neutralizing antibody during last 4 weeks

of 12-weeks high-fat diet

No effect on lesion size

\section{Contrasting effects of CXCR4 antagonists}

Apoe $^{-/-}$treated with CXCR4 antagonist Zernecke et al., 2008

AMD3465

Enhanced mobilization of $\mathrm{Lin}^{-}$Sca1 ${ }^{+}$

cells and leukocytes, predominantly

neutrophils

Increased lesion size with reduced

SMC content, but increased neutrophil

content

Increased apoptosis of plaque cells

"Reversa" mouse treated with

AMD3100 (high-fat diet study)

Enhanced mobilization of progenitor

cells, including "EPCs" (Cd11 b- cKit ${ }^{+}$

$\mathrm{Flk} 1^{+}$or $\mathrm{Cd} 34^{+} \mathrm{Cd} 133^{+} \mathrm{Flk} 1^{+}$)

Enhanced atherosclerosis regression

after plasma lipid normalization

\section{CXCL12/CXCR4 IN PARTIAL LIGATION MODEL (ACCELERATED} ATHEROSCLEROSIS MODEL)

\section{Protective effects of CXCL12/CXCR4 signaling}

Apoe $^{-/-}$with systemic CXCL12

Akhtar et al., 2013

treatment

Enhanced recruitment and

incorporation of bone marrow-derived

$\mathrm{Lin}^{-} \mathrm{Sca}{ }^{+}$cells 


\section{Table 1 | Continued}

\section{Enhanced lesion stability, without \\ effect on lesion size \\ Reduced macrophage content}

Apoe ${ }^{-/-}$with local CXCL12 siRNA Akhtar et al., 2013
treatment
Increased lesion size
Reduced SMC content and increased
macrophage content

\begin{tabular}{|c|c|}
\hline \multicolumn{2}{|l|}{ HUMAN STUDIES } \\
\hline \multicolumn{2}{|l|}{ GWAS } \\
\hline \multicolumn{2}{|l|}{$\begin{array}{l}\text { SNPs rs1746048 (risk allele: C) and } \\
\text { rs501120 (risk allele: T) on Chr10q11.21, } \\
80 \text { Kb downstream of CXCL12 }\end{array}$} \\
\hline $\begin{array}{l}\text { Significantly associated with CAD and } \\
\text { MI risk }\end{array}$ & $\begin{array}{l}\text { Burton et al., 2007; Samani } \\
\text { et al., 2007; Kathiresan et al., } \\
\text { 2009; Schunkert et al., } 2011\end{array}$ \\
\hline $\begin{array}{l}\text { Although genome-wide significance } \\
\text { could not be reached in } 2 \text { other studies }\end{array}$ & $\begin{array}{l}\text { Ripatti et al., 2010; Peden } \\
\text { et al., } 2011\end{array}$ \\
\hline
\end{tabular}

\section{CXCL12 expression}

CXCL12 protective?

$\begin{array}{ll}\text { Significantly reduced CXCL12 plasma } & \text { Damas et al., } 2002 \\ \text { levels in patients with angina, } & \\ \text { especially in unstable angina } & \text { Kiechl et al., } 2010 \\ \text { CAD risk genotype rs501120 (T/T) } & \\ \text { significantly associated with reduced } & \\ \text { CXCL12 plasma levels } & \\ \text { CXCL12 progressive? } & \\ \text { Risk alleles of rs1746048 and rs501120 et al., } 2011 \\ \text { significantly associated with higher }\end{array}$

\section{CXCR4 expression}

Patients with angina show reduced CXCR4 surface expression on peripheral blood cells

myocytes and endothelial cells (Hu et al., 2007; Saxena et al., 2008). Also, delivery of CXCL12 triggered upregulation of vascular endothelial growth factor (VEGF) in the infarcted area and in cardiac endothelial cells, with VEGF an important regulator of angiogenesis and progenitor cell recruitment (Saxena et al., 2008). Furthermore, multiple studies have explored the effect of CXCL12 delivery into the myocardium through local treatment with CXCL12-overexpressing adenovirus, CXCL12transgenic skeletal myoblasts or CXCL12-releasing hydrogels. Such exogenous CXCL12 delivery was associated with enhanced recruitment and incorporation of $\mathrm{CXCR}^{+}{ }^{+}$stem and progenitor cells in the infarcted area (Abbott et al., 2004; Elmadbouh et al., 2007; Segers et al., 2007; Purcell et al., 2012).

Stem cell transplantation during MI seems promising to improve cardiac outcome (Sanganalmath and Bolli, 2013), but it is debated whether this is primarily mediated through direct regeneration of cardiac myocytes or through protective paracrine effects on remodeling or preservation of injured tissue (Liehn et al., 2013b). For example, transplantation of endothelial progenitor cells (EPCs) was associated with increased neovascularization and improved cardiac function after MI and MI/IRI, despite variable effects on inflammation and apoptosis (Schuh et al., 2008, 2012). Overexpression of CXCL12 in transplanted EPCs further increased angiogenesis, however without significant improvement of cardiac function (Schuh et al., 2012). In a complementary approach, transplantation of mesenchymal stem cells (MSCs), which have been described as cardiac precursors, is widely investigated as a potential therapy after MI (Hatzistergos et al., 2010; Dong et al., 2012; Liehn et al., 2013b). Overexpression of CXCL12 in transplanted MSCs improved survival of cardiomyocytes after MI, however without evidence for cardiac regeneration (Zhang et al., 2007). MSCs with transgenic CXCR4 expression displayed increased incorporation into the ischemic area, which was associated with increased angiogenesis, myogenesis and cardiac function (Zhang et al., 2008; Huang et al., 2012). In vitro experiments demonstrated hypoxia to increase CXCR4 expression on MSCs, and CXCR4-mediated migration of MSCs to CXCL12 was shown to require PI3K/AKT signaling (Yu et al., 2010). The CXCL12/CXCR4 axis was also at least partly responsible for the beneficial effects of VEGF-overexpressing MSCs by mediating the recruitment of cardiac stem cells to the infarcted region (Tang et al., 2011). Furthermore, cardioprotective effects of transplanted MSCs were shown to require myocardial CXCR4 expression (Dong et al., 2012).

The efficiency of AMD3100 in mobilizing progenitor cells, including EPCs, from the bone marrow was associated with enhanced accumulation of progenitor cells in the infarcted tissue, enhanced neovascularization and improved cardiac function after single AMD3100 treatment in an MI and MI/IRI model (Jujo et al., 2010, 2013). Similarly, cardioprotective effects were reported of daily AMD3100 injections after MI in rats (Proulx et al., 2007). However, two independent groups revealed a reduced cardiac outcome after MI upon chronic AMD3100 administration (Dai et al., 2010; Jujo et al., 2010). This was either associated with a reduced incorporation of progenitor cells in the infarcted region despite enhanced mobilization (Jujo et al., 2010), or with an increased proliferation of resident cardiac progenitor cells. This latter observation raised the suggestion whether increased proliferation may be linked to reduced differentiation, so whether cardioprotective CXCR4 signaling may be required to direct cardiac progenitors to cardiac commitment to ensure their participation in repair of injured myocardium (Dai et al., 2010).

Interestingly, platelet-surface binding of CXCL12, which correlated with platelet activation, was significantly increased in patients with acute coronary syndrome (ACS) compared to patients with stable angina pectoris, and correlated with the number of circulating hematopoietic progenitor cells (Stellos et al., 2009). Similarly, surface expression of CXCR7 but not CXCR4 was found to be significantly enhanced on platelets from patients with ACS compared to subjects with stable CAD (Rath et al., 2014). These data may be supported by recent findings that CXCL12 upregulates CXCR7 surface availability on platelets (Chatterjee et al., 2014), as will be discussed in more detail later. Of note, platelet CXCR7 surface expression levels above average in patients 
with ACS positively correlated with an increase in the left ventricular ejection fraction as a measure of recovery after MI, suggesting a beneficial effect of CXCL12/CXCR7 signaling on functional recovery in ACS patients (Rath et al., 2014).

\section{Double-edged role of CXCR4 in the ischemic heart}

Despite cardioprotective functions of the CXCL12/CXCR4 axis in the ischemic heart, Cxcr4-heterozygosity in mice reduced infarct size after MI, however without affecting cardiac function. This was explained by a counterbalance of on the one hand reduced neovascularization, and on the other hand reduced inflammation with less neutrophils and a preferential recruitment of $\mathrm{Gr} 1^{\text {low }}$ over inflammatory Gri ${ }^{\text {high }}$ monocytes (Liehn et al., 2011). Likewise, adenovirus-mediated overexpression of CXCR4 in the heart increased infarct size and reduced cardiac function. This was associated with an enhanced recruitment of inflammatory cells, enhanced tumor necrosis factor (TNF) $\alpha$ expression and increased apoptosis of cardiomyocytes (Chen et al., 2010a). On the other hand, deficiency of Cxcr4 specifically in cardiac myocytes did not affect heart function or remodeling after MI (Agarwal et al., 2010).

Together, these studies demonstrate a double-edged role of CXCR4 in the ischemic heart, and require further investigation of the role of CXCR4 and its chemokine ligands in the inflammatory processes associated with MI. In this context, also the alternative CXCR4 ligand MIF is upregulated in myocardium and plasma after MI (Yu et al., 2001, 2003) and can exert cardioprotection. Underlying mechanisms include activation of AMPactivated protein kinase (AMPK) (Miller et al., 2008), reduction of oxidative stress (Koga et al., 2011) or inhibition of $c$-Jun N-terminal kinase (JNK)-mediated apoptosis (Qi et al., 2009). An important role for the chemokine receptor CXCR2 on resident cardiac cells in MIF-mediated myocardial protection after ischemic injury was recently shown (Liehn et al., 2013a), but it remains unclear whether also MIF/CXCR4 signaling in cardiomyocytes may contribute to cardioprotection. Furthermore, MIF-induced recruitment and differentiation of protective EPCs through CXCR4 and CXCR2 may be involved in the cardioprotective effects of MIF (Simons et al., 2011; Asare et al., 2013; Kanzler et al., 2013). On the other hand, adverse effects of MIF through myocardial infiltration of inflammatory cells were revealed after prolonged ischemic injury in both MI and MI/IRI (Gao et al., 2011; White et al., 2013). Although these studies did not examine which MIF receptor was involved, a recent report demonstrated an important role for CXCR2 in mediating MIF-triggered monocyte recruitment in the ischemic heart (Liehn et al., 2013a). But also here, an additional involvement of MIF/CXCR4 interaction in ischemic inflammatory cell recruitment remains unclear. In conclusion, recent data indicate that similarly as CXCR4, MIF plays a double-edged role in myocardial ischemia. However, the relative importance of CXCR4 vs. other MIF receptors as CXCR2, in MIF-mediated effects remain unclear.

\section{CXCR4 IN ARTERIAL INJURY-INDUCED RESTENOSIS}

The CXCL12/CXCR4 axis has been revealed to contribute to injury-induced restenosis, which is a major problem after coronary revascularization. CXCL12 expression is increased after vascular injury through enhanced hypoxia-inducible factor (HIF) $1 \alpha$ expression (Schober et al., 2003; Karshovska et al., 2007) and is preceded and mediated by apoptosis in the injured vessel wall (Zernecke et al., 2005). Systemic treatment of mice with a CXCL12 blocking antibody or a CXCR4 antagonist reduced injury-induced neointimal size and content of smooth muscle cells (SMCs), which are a driving force of neointimal hyperplasia. Similar results were obtained after transplantation with $\mathrm{CxCr} 4^{-/-}$ bone marrow or local treatment with a dysfunctional CXCL12 mutant (Schober et al., 2003; Zernecke et al., 2005; Karshovska et al., 2008; Hamesch et al., 2012). In these studies reduced SMC content was associated with a reduction in injury-induced mobilization of $\mathrm{Lin}^{-} \mathrm{Scal}^{+}$progenitor cells, which were shown to be incorporated into neointimal lesions and capable to differentiate into SMCs (Schober et al., 2003; Zernecke et al., 2005). This corresponded with previous observations that bone marrow-derived cells can be recruited to mechanically injured arteries, where they can differentiate into vascular SMCs (VSMCs) and even endothelial cells (ECs) (Sata et al., 2002; Tanaka and Sata, 2008).

Multiple studies have linked EPCs with enhanced reendothelialization and reduced neointimal hyperplasia after vessel injury (Werner et al., 2003; Kong et al., 2004). CXCR4 was shown to contribute to adhesion of in vitro mononuclear cell-derived EPCs to injured arteries, although to a lesser extent than CXCR2 (Hristov et al., 2007). Whereas CXCR4 blockade interfered with the capacity of infused EPCs to promote reendothelialization and reduce neointimal lesion size after carotid artery injury (Yin et al., 2010; Li et al., 2011), overexpression of CXCR4 promoted CXCL12-triggered migration and adhesion of EPCs in vitro and enhanced their capacity to promote endothelial recovery after vascular denudation in vivo (Chen et al., 2010b). However, it remains debated whether EPCs really affect injury-induced restenosis through direct incorporation in the injured vascular wall, or rather through paracrine effects on resident vascular cells by secreting mitogenic cytokines and growth factors as VEGF (Yoshioka et al., 2006; Iwata et al., 2010; Nemenoff et al., 2011; Hagensen et al., 2012; Merkulova-Rainon et al., 2012).

Furthermore, blockade of CXCR4 was shown to reduce cellular proliferation and the macrophage content of neointimal lesions after femoral artery injury, which was associated with reduced neointimal lesion size (Olive et al., 2008). In the same mouse model, ability of macrophage colony stimulating factor (M-CSF or CSF1) to accelerate injury-induced neointimal hyperplasia was abolished upon treatment with AMD3100. This was associated with reduced lesional incorporation of $\mathrm{CXCR} 4^{+}$cells despite enhanced white blood cell count in the peripheral blood, suggesting a detrimental role for CXCR4 in injury-induced neointimal hyperplasia in mediating the recruitment of inflammatory cells into neointimal lesions (Shiba et al., 2007).

In conclusion, blocking the CXCL12/CXCR4 axis interferes with injury-induced neointimal hyperplasia through reduced recruitment of $\mathrm{CXCR}^{+}{ }^{+}$smooth muscle progenitors and inflammatory cells to the site of injury. On the other hand, CXCR4 enhances the ability of infused EPCs to adhere to injured vessels and promote reendothelialization. Although these data derive from in vitro cultured EPCs, which may behave different than the rather vaguely defined "circulating EPCs" (Steinmetz et al., 2010; 
Rennert et al., 2012), the current findings suggest a double-edged role for CXCR4 in injury-induced restenosis through recruitment of (progenitor) cells that either stimulate or interfere with neointimal hyperplasia. Such double-edged function was recently also observed upon tamoxifen-induced endothelial-specific deficiency of Cxcr4 $\left(C x c r 4^{E C-K O}\right)$ in apolipoprotein E-deficient $\left(A p o e^{-/-}\right)$ mice, which significantly decreased mobilization of both circulating Sca $1^{+} \mathrm{Flk}^{+} \mathrm{Cd} 31^{+}$cells, often referred to as EPCs, and of $\mathrm{Lin}^{-} \mathrm{Sca}{ }^{+}$cells upon wire-mediated injury of the carotid artery. Furthermore, $C x c r 4^{E C-K O} A p o e^{-/-}$mice showed a reduced reendothelialization efficiency, which was linked with a decrease in endothelial wound healing and in vivo proliferation. As a net result, endothelial-specific Cxcr4 deficiency triggered the formation of larger neointimal lesions, displaying an increase in inflammatory macrophages but a reduced SMC content (Noels et al., 2014). Whether CXCR4 signaling also affects specific functions of VSMCs or macrophages in context of vascular injury remains to be investigated.

\section{CXCR4 IN NATIVE ATHEROSCLEROSIS: PROGENITOR CELL MOBILIZATION \\ Vascular progenitor cells}

In contrast to conditions of MI and injury-induced restenosis, not much is known about a potential involvement of bone marrow-derived vascular progenitor cells in native atherosclerosis, as has been recently summarized for EPCs (Du et al., 2012) and vascular smooth muscle progenitor cells (SPCs) (MerkulovaRainon et al., 2012). It was shown that infusion of EPCs as well as treatment with AMD3100, which triggered EPC mobilization, enhanced plaque regression after normalization of plasma lipid levels in Reversa mice (Yao et al., 2012). In contrast, a study in Apoe ${ }^{-/-}$mice did not reveal an atheroprotective effect of systemic AMD3100 treatment, but rather found AMD3100 to abolish beneficial effects of apoptotic body treatment on atherosclerosis. Endothelial apoptotic bodies were shown to contain miRNA126, which is transferred to neighboring ECs to induce the expression and release of CXCL12 by unleashing autoregulatory CXCR4 signaling. Injection of EC-derived apoptotic bodies into Apoe $e^{-/-}$ mice increased CXCL12 expression in atherosclerotic lesions and promoted progenitor cell mobilization and their recruitment to the endothelial lining of the lesions. Lesions of mice treated with apoptotic bodies were generally smaller in size and exhibited a less inflammatory phenotype with reduced macrophage and apoptotic cell content (Zernecke et al., 2009). Thus, despite contradictory findings on the effect of AMD3100 treatment, both studies suggest an atheroprotective function for CXCL12/CXCR4 signaling through mobilization of protective EPCs. Interestingly, it was revealed that patients with CAD show lower levels and a decreased migratory response of circulating EPCs (Vasa et al., 2001). In addition, systemic treatment of mice with CXCL12 in a partial ligation model — which induces advanced atherosclerotic lesions with an unstable phenotype-enhanced the recruitment of $\mathrm{Lin}^{-} \mathrm{Scal}^{+}$SPCs and promoted a more stable plaque phenotype (Akhtar et al., 2013). Such plaque-stabilizing role for SPCs was also suggested earlier by Zoll et al, who showed that injection of SPCs reduced atherosclerotic lesion size and improved lesion stability (Zoll et al., 2008). Together, these studies reveal an atheroprotective function for CXCL12/CXCR4 signaling through recruitment of protective EPCs and plaque-stabilizing SPCs.

However, others reported on an atheroprogressive role for vascular progenitor cells. Inducing apoptosis of rare lesional bone marrow-derived SMCs substantially decreased plaque size (Yu et al., 2011a), and George et al. found EPC transfer to increase atherosclerosis in mice (George et al., 2005). Contradictory findings on the presence or function of vascular progenitor cells in chronic atherosclerosis may be related to the atherosclerosis model, lesion stage, but also on the vague definition of such progenitor cells. Further research is definitively needed to improve phenotypical and functional characterization of vascular progenitor cell subsets in context of atherosclerosis before a role of the CXCR4/CXCL12 axis in their mobilization and potential functions in this pathology can be investigated in detail.

\section{Hematopoietic progenitor cells}

Interestingly, MI was recently revealed to accelerate atherosclerosis in mice. MI reduced CXCL12 expression in bone marrow through sympathetic nervous system activity and signaling through $\beta 3$ adrenergic receptor ( $\beta 3 \mathrm{AR}$ or ADRB3). In this way, MI enhanced mobilization of HSPCs from bone marrow niches and their hosting in the spleen, triggering myelopoiesis and increased atherosclerosis up to 3 months after coronary ligation (Dutta et al., 2012). Although the latter study did not address the underlying mechanisms of CXCL12 upregulation upon $\beta 3 \mathrm{AR}$ blocking nor examine potential effects on CXCR4 expression or function, LaRocca et al. revealed a direct (physical) interaction of $\beta 2$ adrenergic receptors with CXCR4 resulting in the modification of the contractile nature of cardiomyocytes (Larocca et al., $2010)$. It is further known that $\beta 2$ - and $\beta 3$ adrenergic receptors cooperate during progenitor cell mobilization with partial functional redundancy under stress (Mendez-Ferrer et al., 2010). Hence, one may speculate that Cxcr4 may also functionally interact with other adrenergic receptors, like $\beta 3 \mathrm{AR}$, in a direct or indirect way.

\section{CXCR4 IN NATIVE ATHEROSCLEROSIS: CELL TYPE-SPECIFIC FUNCTIONS?}

In addition to a role for CXCR4 through progenitor cell mobilization, CXCR4 may affect native atherogenesis by modifying atherosclerosis-relevant cellular functions. CXCR4 expression has been described on many cell types including monocytes and macrophages, neutrophils (Bruhl et al., 2003), T-cells (Murphy et al., 2000), B-cells (Nie et al., 2004), mature ECs (Gupta et al., 1998), and SMCs (Nemenoff et al., 2008; Jie et al., 2010). All of these cells play distinct roles in the pathophysiology of atherosclerosis, but not much is known about the precise role of CXCR4 in individual cellular responses.

\section{Monocytes and macrophages}

Monocytes and macrophages have been proven to be of outstanding importance in the progression and development of mature atherosclerotic lesions and their depletion has been recognized atheroprotective already 20 years ago (Ylitalo et al., 1994). As the picture grows it becomes more and more evident that depletion of individual cell subsets does not serve as 
a realistic therapeutic approach, hence understanding the details of cell-cell interactions and communication gains importance (Weber and Noels, 2011).

\section{CXCR4 expression and potential functions: studies of human cells} Macrophages and foam cells. CXCR4 is expressed on all monocyte subsets, with highest expression on classical human monocytes. This contrasts with observations in mice, which show highest CXCR4 levels on non-classical monocytes (Ingersoll et al., 2010), as will be discussed later in more detail. Gupta et al. revealed high expression of CXCR4 on human blood monocytes, which declined while they differentiated into macrophages, but restored again after $24 \mathrm{~h}$, peaking at 7 days. Interestingly, CXCR4 expression on macrophages could be further upregulated by stimulation with oxidized low-density lipoprotein (oxLDL). From here the authors conclude that, although there is no direct evidence, restoration of CXCR4 expression on lesional macrophages and its further up-regulation by oxLDL during foam cell formation may contribute to migration of intimal foam cells and the subsequent progression of plaque growth (Gupta et al., 1999). Furthermore, CXCL12/CXCR4 signaling was linked with enhanced macropinocytosis in leukocytes (Tanaka et al., 2012), suggesting that a lack of CXCR4 may also influence (modified) lipid accumulation in macrophages and other lesional cells. In contrast, a recent study found CXCL12 to induce phagocytosis and the uptake of acetylated LDL in THP1-derived macrophages specifically through binding CXCR7 but not CXCR4 (Ma et al., 2013). In this context, the CXCR7 agonist CCX771 was recently shown to increase the uptake of very low-density LDL (VLDL) in adipocytes. Correspondingly, treatment of $A p o e^{-/-}$mice with CCX771 reduced the levels of circulating VLDL and decreased atherosclerosis (Li et al., 2014). Whether similar mechanisms can be identified in other cell types as macrophages remains to be examined, as are the exact mechanisms underlying CXCR7mediated uptake of VLDL or modified lipids.

Patients with CAD. In patients with stable and unstable angina pectoris CXCR4 surface expression on peripheral blood mononuclear cells (PBMCs) was decreased and CXCL12 levels in patients with unstable angina pectoris were explicitly low. However, in vitro treatment of PBMCs from these patients with high concentrations of CXCL12 reduced mRNA and protein levels of chemokine ligands CCL2 and CXCL8, MMP9 and tissue factor, while increasing tissue inhibitor of metalloproteinases (TIMP) 1. Therefore, high (local) concentrations of CXCL12 may mediate anti-inflammatory and matrix-stabilizing effects promoting plaque stabilization and may be beneficial in angina pectoris and ACSs (Damas et al., 2002). Another study showed autocrine CXCL12 signaling to downregulate expression of runt-related transcription factor (RUNX) 3 in human monocytes/macrophages, thereby promoting a pro-angiogenic, but immunosuppressive phenotype of these cells (Sanchez-Martin et al., 2011).

Compounds regulating CXCR4. Several compounds were identified to modify CXCR4-mediated immune responses in vitro. Glucocorticoids have been demonstrated to upregulate CXCR4 expression on human blood monocytes and Caulfied et al. assume that increased CXCR4 expression sensitizes monocytes to tissue resident CXCL12, guiding monocytes away from sites of inflammation with supposingly lesser local CXCL12 release (Caulfield et al., 2002). The latter most likely contradicts another study, which revealed high expression of CXCL12 in SMCs, ECs and macrophages in human atherosclerotic plaques but not in normal vessels (Abi-Younes et al., 2000). This would rather argue for a chemotactic gradient of CXCL12 toward the site of inflammation, although this might be disease- and cell type-dependent.

As a second example, monocyte CXCR4 expression has been shown to be modulated by hydrogen sulfide $\left(\mathrm{H}_{2} \mathrm{~S}\right)$ donors. $\mathrm{H}_{2} \mathrm{~S}$ donors have lately been recognized as vasoprotective agents and changes in $\mathrm{H}_{2} \mathrm{~S}$ may affect atherosclerosis. Interestingly, a synthetic slow $\mathrm{H}_{2} \mathrm{~S}$ releaser (GYY4137) inhibited oxLDL-induced foam cell formation and cholesterol esterification in RAW264 cells and primary human monocytes, which was accompanied by decreased CXCR4 expression (Liu et al., 2013). In contrast, angiotensin-converting enzyme (ACE) inhibitors, widely used to treat high blood pressure by interfering with the reninangiotensin system, did not affect CXCR4 expression on primary human monocytes and THP1 cells (Apostolakis et al., 2007). The same group also assessed if angiotensin I and II treatment would have a direct impact on chemokine receptor expression on THP1 cells, again CXCR4 expression was not altered (Apostolakis et al., 2010).

Conjugated linoleic acids (CLA) were shown to influence human peripheral blood monocyte function by suppressing CD18 expression, thereby reducing the number of $\beta 2$-integrins expressed on the external surface and decreasing adhesion to activated ECs. In addition, CLA reduced CXCR4 expression, resulting in an only minor initiation of "inside out" signaling. As a result, partial, but incomplete, activation of $\beta 2$-integrins further reduces adherence of leukocytes and their migration to CXCL12 (De Gaetano et al., 2013).

Statins, which lower intracellular cholesterol synthesis, are the gold standard to treat hyperlipidemia-associated atherosclerosis, but have also been reported to cause numerous other pleiotropic effects. To examine if statin withdrawal would affect human monocyte subsets in patients with stable CAD, statin treatment was cut off for 2 weeks. Subsequent evaluation of blood monocyte subsets did not reveal any differences in numbers, but downregulation of Toll-like receptor (TLR) 4 on all subsets and decreased expression of CXCR4 on classical monocytes $\left(\mathrm{CD}_{14}{ }^{++} \mathrm{CD}^{-} 6^{-}\right.$) (Jaipersad et al., 2013). Interestingly, high doses of statin treatment were also shown to reduce general CXCL12 plasma levels in hyperlipidemic patients (Camnitz et al., 2012). However, it remains elusive whether statin treatment and a subsequent increase in CXCR4 expression, but decreased CXCL12 titers, point at a direct pro- or anti-atherosclerotic role of the CXCL12/CXCR4 axis.

Another mechanism, recently recognized to drive atherosclerotic lesion growth, is hypoxia (Marsch et al., 2013). Notably, hypoxia-induced upregulation of the transcriptional activator HIF1 triggers CXCR4 mRNA and protein expression in human monocytes. In addition, these cells showed increased migration toward CXCL12 under hypoxic conditions. Based on these 
findings the authors conclude that the hypoxia-HIF1-CXCR4 pathway may regulate cell trafficking and localization into hypoxic tissues, such as atherosclerotic lesions (Schioppa et al., 2003).

In contrast, CXCR4 expression on macrophages was suppressed in the presence of M-CSF. Increased M-CSF titers have been implicated in the pathogenesis of atherosclerosis and it was shown that M-CSF delivers a pro-atherogenic signal to human macrophages by stimulation of cholesterol accumulation and pro-inflammatory chemokine secretion. Thus, M-CSF-induced suppression of macrophage CXCR4 expression may point at an atheroprotective function of downstream CXCR4 signaling events (Irvine et al., 2009).

CXCR4 expression and potential functions: mouse studies. The above-mentioned studies on human monocytes and macrophages suggest diverse potential roles for CXCR4 in atherosclerosis, still mouse studies are equally elusive, without a clear indication for a pro- or anti-atherogenic role for CXCL12/CXCR4. In contrast to human monocytes, CXCR4 in mouse is higher expressed on nonclassical monocytes and it is not clear if this does necessarily imply functional differences in individual mouse and human monocyte subsets or not (Ingersoll et al., 2010).

One study reported an interesting finding using a mutant non-heparin sulfate-binding CXCL12 (HSmCXCL12). In vitro, HSmCXCL12 failed to promote transendothelial migration of PBMCs if used as chemoattractant in the bottom well of transwell plates, and inhibited the haptotactic response to wild-type CCL7, CXCL12, and CXCL8. Further, intravenous administration of HSmCXCL12 into mice also repressed the recruitment of lymphocytes and mononuclear phagocytes to air pouches injected with CXCL12. Moreover, repetitive administration of HSmCXCL12 in vivo reduced leukocyte-surface expression of CXCR4, and CXCL12-induced chemotaxis and adhesion. From here the authors conclude that non-heparin sulfate-binding variants of CXCL12 can mediate a powerful anti-inflammatory effect through induction of chronic CXCR4 internalization on leukocytes in vivo. Subsequently, this leads to receptor desensitization putatively explaining the functional deficits of these leukocytes (O'boyle et al., 2009). Hence, it could be interesting to carefully dissect the differential functional consequences of receptor desensitization through receptor internalization compared to CXCR4 blocking with AMD as reported by Zernecke et al. (2008).

A potential pro-inflammatory role for wild-type CXCL12 may also be deduced from findings from Liu et al., who revealed decreased CXCR4 expression on RAW264 cells and primary human monocytes treated with the $\mathrm{H}_{2} \mathrm{~S}$ releaser GYY4137, which was introduced above. Administration of GYY4137 into Apoe ${ }^{-/-}$ mice receiving a high-fat diet for 4 weeks decreased atherosclerotic plaque formation and partially restored aortic endotheliumdependent relaxation. Further, intercellular adhesion molecule (ICAM) 1 , TNF- $\alpha$ and interleukin (IL) 6 mRNA expression as well as superoxide generation in the aorta declined in mice treated with GYY4137 (Liu et al., 2013). Similarly, and again paralleling in vitro studies with human monocytes, CLA treatment of $A p o e^{-/-}$mice with already pre-established atherosclerosis induced lesion regression by reducing leukocyte adhesion and decreasing CD18 expression on classical monocytes (De Gaetano et al., 2013).

The above studies may point at a pro-atherogenic role of CXCR4 signaling in atherosclerosis; however this may strongly depend on the binding partner interacting with CXCR4. As already described, CXCL12 is not the only ligand for CXCR4 and MIF, an alternative ligand for CXCR4, has a strong proatherogenic impact. In this context, Bernhagen et al. revealed that antibody mediated-neutralization of MIF, but not CXCL12, induced atherosclerotic lesion regression in $\mathrm{Apoe}^{-/-}$mice (Bernhagen et al., 2007). In line, knock-out of Mif in $\mathrm{Ldll}^{-/-}$ mice did also result in diminished atherosclerosis (Pan et al., 2004). This suggests potential different roles of CXCR4 and its ligand CXCL12 in atherosclerosis through interplay of CXCR4 with MIF. Similarly, interplay of CXCL12 with other signaling molecules may modify its inflammatory effects. For example, hetero-complexes of high mobility group box (HMGB) 1 and CXCL12 were reported to induce inflammatory cell recruitment to injured tissue, which was not the case for each compound alone. Further, these complexes exclusively bound to CXCR4 inducing a conformational rearrangement of CXCR4, which differed from the single binding of CXCL12 to its receptor (Schiraldi et al., 2012).

\section{Neutrophils}

Treatment of mice with the CXCR4 antagonist AMD3100 induced cell egress from the bone marrow (Schiraldi et al., 2012), which is in line with findings by Zernecke et al. who described increased leukocytosis, mostly neutrophil mobilization, and enhanced lesion formation in Apoe ${ }^{-/-}$receiving a cholesterol-rich diet for 12 weeks while supplemented with AMD. Interestingly, monocyte numbers were only moderately enhanced in these mice and, according to the authors, lesion growth was mainly attributable to increased plaque neutrophils and enhanced apoptosis (Zernecke et al., 2008).

Notably, a growing body of evidence underlines the role of neutrophils in atherogenesis (Drechsler et al., 2010, 2011; Doring et al., 2012) and it was recognized that the CXCL12/CXCR4 axis maintains neutrophil homeostasis primarily by regulation of neutrophil release from the bone marrow in a cell-autonomous fashion (Eash et al., 2009). It was further implicated that senescent neutrophils in the periphery expressing high levels of CXCR4 home back to the bone marrow to be cleared (Martin et al., 2003). In contrast, activated neutrophils downregulate CXCR4 expression putatively postponing their clearance (Bruhl et al., 2003; Martin et al., 2003).

\section{Lymphocytes}

CXCR4 on lymphocytes plays an essential role during B-cell development (Nagasawa et al., 1996) and T-cell homeostasis (Bleul et al., 1996b; Zou et al., 1998). Furthermore, the CXCL12/CXCR4 axis drives chemotaxis or fugetaxis of T-cells in various pathophysiological settings (Poznansky et al., 2000; Dunussi-Joannopoulos et al., 2002; Fernandis et al., 2003; Okabe et al., 2005; Zhang et al., 2005). Similarly, CXCL12 is able to trigger B-cell chemotaxis in vitro through CXCR4 (Klasen et al., 2014). 
It became evident that the impact of $\mathrm{B}$ - and T-cells in atherosclerosis is strongly subset-dependent. While e.g., Th1 responses are known to be pro-atherosclerotic, regulatory T-cells haven been proven to be protective. Similarly, B1- and B2cells exhibit diverse functions in lesion development (Weber and Noels, 2011). Nevertheless, studies dissecting the role of CXCR4 on $\mathrm{T}$ - and B-cells in the context of atherosclerosis are scarce. Two independent groups showed that lysophosphatidylcholine (LPC), a main phospholipid component of oxLDL, upregulates CXCR4 expression on Jurkat cells and human blood CD4 ${ }^{+} \mathrm{T}_{-}$ cells. Further, the chemotactic ability of $\mathrm{CD} 4^{+}$T-cells toward CXCL12 and their production of pro-inflammatory cytokines were increased in the presence of LPC. Hence, the ill alliance of LPC and CXCL12 in atherosclerotic lesions may amplify proinflammatory responses by stimulation of $\mathrm{CD}^{+}{ }^{+} \mathrm{T}$-cells and subsequent plaque growth (Han et al., 2004; Hara et al., 2008). Interestingly, it was also shown that excess of mineralocorticoids, mainly aldosterone, drive $\mathrm{CAD}$ by cardiac and renal fibrosis, as well as hypertension. Here, Chu et al. imply a specific role of the CXCL12/CXCR4 axis in the detrimental consequences of mineralocorticoid excess and render CXCL12 explicitly responsible for the accumulation of T-cells in fibrotic tissue (Chu et al., 2011). From patients with abdominal aortic aneurysm (AAA) we further learn that $\mathrm{T}$ - and B-cells recruited to sites of AAA express high levels of CXCR4 and exhibit a pro-inflammatory signature. Hence, CXCR4/CXCL12 interactions may strongly impact on the recruitment and retention of inflammatory lymphocytes infiltrating AAAs (Ocana et al., 2008). In contrast, acute stress induced by public speaking did not enhance the number of CXCR4 expressing T-cells, but increased the frequency of T-cells expressing CXCR2, CXCR3, and CCR5. Therefore, cardiac sympathetic activation may lead to EC and T-cell activation subsequently driving acute flooding of atherosclerotic lesions with pro-inflammatory mediators (Bosch et al., 2003).

In addition to CXCL12-triggered effects, CXCR4 is able to mediate MIF-induced B-cell chemotaxis, and T-cell chemotaxis and arrest in vitro (Bernhagen et al., 2007; Klasen et al., 2014). Blockade of MIF in Apoe $e^{-/-}$mice on high-fat diet resulted in the formation of smaller atherosclerotic lesions displaying a reduced macrophage and T-cell content, supporting a role for MIF in Tcell chemotaxis also in the context of atherosclerosis (Bernhagen et al., 2007).

\section{Platelets}

CXCR4 expression (mRNA, protein) was reported on platelets (Wang et al., 1998; Kowalska et al., 1999) and although platelets lack nuclei and many organelles and are mainly known for their important role in blood coagulation, their impact on immunological and inflammatory responses, in particular atherosclerosis, should not be underestimated (Lievens and Von Hundelshausen, 2011). Addition of CXCL12 to platelets from healthy donors induced platelet aggregation, which could be inhibited by blocking CXCR4. The latter implies an atherogenic, pro-thrombotic, and plaque-destabilizing role for the CXCL12/CXCR4 axis in vivo (Falk et al., 1995; Abi-Younes et al., 2000). In contrast, others report CXCL12 to be a weak platelet agonist, however still amplifying platelet activation, adhesion and chemokine release triggered by low doses of primary platelet agonists, such as adenosine diphosphate (ADP) and thrombin, or arterial flow conditions (Kowalska et al., 1999; Gear et al., 2001). Furthermore, CXCL12 gradients could induce platelet migration and transmigration in vitro involving PI3K signaling (Kraemer et al., 2010). In addition, recent work showed CXCL12 to trigger CXCR4 internalization and cyclophilin A-dependent CXCR7 externalization on (mouse and human) platelets, resulting in prolonged platelet survival. Mice lacking the cytosolic chaperone cyclophilin A showed less CXCL12-induced rescue of platelets from activation-induced apoptosis through CXCR7 engagement. Hence, differential regulation of CXCR4/CXCR7 surface expression on platelets upon CXCL12 exposure at sites of platelet activation/accumulation may orchestrate platelet survival, subsequently impacting on plateletmediated physiological mechanisms (Chatterjee et al., 2014).

\section{Vascular Endothelial Cells}

CXCR4 expression in arterial ECs. Expression of CXCR4 on various types of vascular ECs has been widely reported (Hillyer et al., 2003), however, it should be emphasized that ECs are a very heterogeneous population, with ECs from different anatomic sites differing in basal gene expression, localization and function (Aird, 2007). Further, one has to carefully distinguish between expression on venous and arterial ECs (Dela Paz and D'amore, 2009). Unfortunately, many studies extrapolate e.g., in vitro findings generated with human umbilical vein endothelial cells (HUVECs) to arteriosclerosis, which is at least daring.

In a study examining CXCR4 expression following vessel wall injury in porcine coronary arteries, CXCR4 expression could be shown 24 h to 7 days after injury, but only in lymphocytes, granulocytes and myelo-fibroblasts entering the injured tissue (Jabs et al., 2007). However, others investigated CXCR4 expression in human carotid artery specimens, where CXCR4 was abundantly expressed by lesional ECs and only marginally in minimally diseased endothelium (Molino et al., 2000; Melchionna et al., 2005). Similarly, Gupta et al. showed CXCR4 mRNA expression in human coronary artery ECs, although it is not clear if these cells originated from inflamed or steady-state endothelium (Gupta et al., 1998). CXCR4 was also shown to be expressed (mRNA and protein) by cultured bovine aortic ECs (BAECs), in cryo-sections of rabbit thoracic aortas (Volin et al., 1998) and in mouse aortic endothelium (Melchionna et al., 2010). For BAECs it was further demonstrated that resting BAECs accumulate CXCR4 protein in cytoplasmic granules, while migrating BAECs display a diffuse surface expression of CXCR4 (Feil and Augustin, 1998).

In addition, in vitro studies with human aortic ECs (HAECs) revealed enhanced CXCR4 surface expression and CXCL12induced chemotaxis in the presence of VEGF or basic fibroblast growth factor (bFGF) $48 \mathrm{~h}$ after stimulation. Notably, interferon (IFN)- $\gamma$, lipopolysaccharide (LPS) or CXCL12 did not elevate the surface expression of CXCR4 (Salcedo et al., 1999).

CXCR4 expression in venous and microvascular ECs. Upregulation of CXCR4 surface expression after addition of VEGF and bFGF was also seen in human microvascular ECs and HUVECs (Salcedo et al., 1999, 2003). In contrast, Schutyser et al. do not report changes in CXCR4 mRNA expression in human 
microvascular ECs after treatment with VEGF, but describe augmented CXCR4 expression (mRNA and protein) after serum starvation and/or hypoxic treatment of microvascular ECs (Schutyser et al., 2007). Further, hypoxia is also an important regulator of the CXCL12/CXCR4 axis in HUVECs by enhancing CXCR4 expression (Ceradini et al., 2004; Jin et al., 2012). In general hypoxia does cause lowering of local $\mathrm{pH}$, and $\mathrm{pH}$ changes are also known to occur upon physical exercise and hemodynamic shear stress, as well as in pathological states including cardiac ischemia. In this context Melchionna et al. reported that acidosis decreased CXCR4 surface expression on mouse aortic ECs in vivo and on HUVECs in vitro in a HIF1 $\alpha$-dependent manner (Melchionna et al., 2010).

Notably, mouse microvascular ECs were also shown to augment CXCR4 expression in vitro in response to erythromycin, an anti-inflammatory antibiotic drug used for treatment of chronic inflammatory diseases. The authors assume that beneficial effects of erythromycin are partly due to CXCR4-expressing ECs recruited to sites of tissue injury (Takagi et al., 2009). However, since microvascular ECs also comprise a broad variety of ECs, for example of dermal, brain, heart or pancreatic islets origin, it remains elusive how any differential regulation of CXCR4 expression described above would impact on atherosclerotic plaque development.

Role of CXCR4 in ECs? Concerning possibly relevant functions of endothelial CXCR4 signaling in context of atherosclerosis, several putatively athero-relevant findings were described in HUVECs, but confirmations in arterial ECs are pending. For example, laminar shear stress suppresses CXCR4 expression in HUVECs while low shear stress favors CXCR4 expression, subsequently resulting in increased EC apoptosis and CCL2 and CXCL8 release (Melchionna et al., 2005).

Another study revealed enhanced release of CXCL12 by HUVECs after oxLDL treatment and a subsequently increased migratory and adhesive response of MSCs (Li et al., 2010). It was further demonstrated that MIF facilitates leukocyte rolling on stimulated HUVECs while siRNA-mediated knock-down of endothelial MIF resulted in decreased expression of E-selectin, ICAM-1, vascular cell adhesion molecule (VCAM) 1, CXCL8, and CCL2 (Cheng et al., 2010).

In addition, it seems that not only VEGF may regulate CXCR4 expression, but it was also shown that CXCL12 treatment increased VEGF protein expression in human microvascular ECs after serum starvation (Saxena et al., 2008), underlining the role of CXCL12 in angiogenesis. Given the CXCL12/CXCR4 axis to be angiogenic in general (Ara et al., 2005; Unoki et al., 2010), but also in tumor development (Domanska et al., 2013) and potentially in atherosclerotic lesions (Di Stefano et al., 2009), and angiogenesis being considered to increase plaque vulnerability, the question still remains if this reflects an important unfavorable role of CXCR4 in atherosclerosis. In a different approach, blocking of TLR2 resulted in increased angiogenic capacity of HUVECs, putatively mediated via association of TLR2 with CXCR4 and subsequently enhanced CXCR4 signaling. Consequently, knock-down of CXCR4 in the presence of TLR2 blocking antibodies revealed less angiogenesis. From these data the authors conclude that TLR2 blocking might serve as a promising therapeutic approach in e.g., MI or peripheral artery disease by promoting revascularization. However, considering angiogenesis pro-atherogenic, TLR2 blocking might have detrimental consequences in the context of plaque stability and development, as already mentioned above (Wagner et al., 2013). Nevertheless, it was also shown that the inflammatory mediators IFN- $\gamma$ and TNF- $\alpha$ decrease CXCR4 and CXCL12 expression in HUVECs, thereby decreasing their angiogenic capacity (Gupta et al., 1998; Salvucci et al., 2004). Interestingly, the latter contradict findings from Salcedo et al, who showed no difference in CXCR4 expression in HAECs after IFN- $\gamma$ treatment (Salcedo et al., 1999). Yet, it should be emphasized again that HUVECs and HAECs might exert totally different responses in the presence of the same stimulus, underlining again the importance of caution in generalizing findings from ECs of different origin.

\section{Vascular smooth muscle cells}

VSMCs are highly specialized cells controlling contraction and regulation of blood vessel diameter, blood pressure, and blood flow. Moreover, VSMCs play a critical role in secretion of extracellular matrix components, which determine the mechanical properties of mature blood vessels. Differentiated VSMCs in adult blood vessels proliferate at very low rates and retain high plasticity, which enables changes in phenotype, referred to as phenotypic switching (Owens et al., 2004). Phenotypic switching of VSMCs is considered an important pathophysiological mechanism in atherosclerosis (Gomez and Owens, 2012).

CXCR4 expression in vascular SMCs. Not much is known about the expression and function of CXCR4 in mature VSMCs. Several studies reported no CXCR4 expression on human or bovine (aortic) SMCs (Gupta et al., 1998; Volin et al., 1998). In contrast, Schecter et al. were the first to claim a functional CXCR4 expression on human aortic SMCs, as the addition of CXCL12 or envelope proteins of HIV specifically binding CXCR4 did induce tissue factor activity in human aortic SMCs (Schecter et al., 2001). Similarly, it was demonstrated that HIV can infect arterial (lesional) human SMCs and blocking CXCR4 in human aortic SMCs in vitro did significantly reduce their viral load. Again, direct expression of CXCR4 on aortic SMCs was not investigated. Yet, the authors still claim that HIV infection of VSMCs through CXCR4 may be one reason why HIV patients are more susceptible to develop atherosclerosis (Eugenin et al., 2008). Nevertheless, Li et al. revealed CXCR4 protein expression on human saphenous vein SMCs (Li et al., 2009) and others later reported CXCR4 expression (RNA, protein) on mouse medial SMCs (Nemenoff et al., 2008), rat aortic SMCs (Jie et al., 2010; Pan et al., 2012) and human aortic SMCs (Weber et al., unpublished data).

Role of CXCR4 in vascular SMCs? As mentioned before, phenotypic switching of VSMCs from a contractile to a synthetic secretory phenotype and their assumed migration from the medial to the intimal arterial wall, where they secrete pro-inflammatory mediators, is considered a pathophysiological mechanism in atherogenesis (Gomez and Owens, 2012). On the other hand, intimal SMCs do also stabilize atherosclerotic lesions by fibrous 
cap formation. This contrasts the pathology of injury-induced restenosis and neointimal hyperplasia, which are mainly driven by SMC proliferation. Hence, the contribution of SMCs to lesion formation is strongly context-dependent.

In a rat model of diabetes, a metabolic disorder associated with a higher prevalence of atherosclerosis, high glucose levels were shown to trigger activation, proliferation, and enhanced chemotaxis of VSMCs via stimulation of the CXCL12/CXCR4 axis (Jie et al., 2010). Correspondingly, salvianolic acid B (Salvia miltiorrhiza), used to treat cardiovascular diseases in traditional Chinese medicine, was shown to inhibit CXCL12/CXCR4-mediated proliferation, migration and subsequently neointimal hyperplasia by VSMCs in a balloon angioplasty-induced neointima formation model in rats. Here salvianolic acid B directly decreased surface expression of CXCR4 on aortic rat SMCs (Pan et al., 2012).

Further, lesion reduction in $\mathrm{Mif}^{-/-} \mathrm{Apoe^{-/- }}$ mice was attributed to a reduction in lesional SMC proliferation, cysteine protease expression, and elastinolytic and collagenolytic activities (Pan et al., 2004). Notably, oxLDL, supposed to be an important trigger of atherogenesis and plaque growth, was shown to induce rat aortic SMC proliferation. This effect could even be further enhanced by addition of CXCL12 and came along with diminished SMC apoptosis. It remains open if this effect would be beneficial through plaque stabilization, or detrimental because of intimal hyperplasia, as discussed above (Li et al., 2013). As mentioned before, vein graft failure after bypass grafting is a major problem and may be associated with neointimal hyperplasia and accelerated atherosclerosis. In this context, Zhang et al. demonstrate that CXCL12/CXCR4 signaling might be a crucial step in vein graft atherosclerosis and contribute to SMC-mediated vein graft neointimal hyperplasia in mice. Furthermore, CXCR4mediated recruitment of inflammatory (progenitor) cells to the vein graft may add to this picture (Zhang et al., 2012).

Also, it was described that CXCL12 stimulates pro-MMP2 expression in human aortic SMCs via CXCR4 in association with the epidermal growth factor receptor in vitro. The authors conclude that CXCR4 expands its signaling repertoire by crosstalking with other receptors, pointing at an important role of ligands engaged in receptor cross-talk as critical players in CAD (Kodali et al., 2006).

\section{GENOME-WIDE ASSOCIATION STUDIES REVEAL CXCL12 AS AN IMPORTANT CANDIDATE GENE IN CAD}

Genome-wide association studies of European ancestry revealed 2 single nucleotide polymorphisms (SNPs) on locus 10q11.21, 80 $\mathrm{kB}$ downstream of CXCL12, to be significantly associated with CAD and MI (Burton et al., 2007; Samani et al., 2007; Kathiresan et al., 2009; Farouk et al., 2010; Schunkert et al., 2011), although genome-wide significance was not reached in 2 other studies (Ripatti et al., 2010; Peden et al., 2011) (Box 4). Whether and how the risk alleles of these SNPs rs1746048(C/C) and rs501120(T/T) affect expression level and/or function of the CXCL12 protein is currently still unclear.

A significant association was revealed between the CAD risk genotype for rs501120 (T/T) and reduced CXCL12 plasma levels (Kiechl et al., 2010). Likewise, patients with angina displayed reduced CXCL12 plasma levels compared to healthy controls. The reduction was even higher in case of unstable disease (Damas et al., 2002), suggesting an atheroprotective role for CXCL12. Remarkably, patients with angina showed a significant reduction in CXCR4 surface expression on PBMCs, despite increased levels of CXCR4 RNA transcripts, but its connection to disease remains unclear (Damas et al., 2002).

In contrast, a recent study revealed the risk alleles of these SNPs to be associated with higher CXCL12 plasma levels, rather suggesting a pro-atherogenic role for CXCL12 (Mehta et al., 2011). Additional large-scale studies in human patients with CAD/MI investigating CXCL12 plasma levels in relation to SNPs and disease would be helpful to get better insight into the role of CXCL12 in this pathology. Furthermore, animal studies are definitively required to unravel disease-associated functions in a cell-specific and molecular way.

Also for the alternative CXCR4 ligand MIF, SNPs have been identified that are associated with cardiovascular disease, as recently summarized (Tillmann et al., 2013). Although the effect of these SNPs on MIF expression or function remain unknown, enhanced MIF plasma levels in patients with ACS (Muller et al., 2012) and the identification of a high MIF plasma level as a risk factor for adverse coronary events in CAD patients with impaired glucose tolerance or type 2 diabetes mellitus (Makino et al., 2010) may support a pro-inflammatory role of plasma MIF in CAD.

\section{CLINICAL PERSPECTIVES AND CONCLUSION}

In conclusion, the role of CXCR4 in native atherosclerosis remains elusive, with only few isolated studies shedding some light on the effect of CXCL12/CXCR4 signaling on cell type-specific functions involved in inflammation or atherosclerosis. In contrast, the CXCL12/CXCR4 axis has been better explored in context of injury-induced restenosis and myocardial ischemia, in which a role for this chemokine ligand/receptor axis has mostly been linked to the mobilization and recruitment of progenitor cells and, to a lesser extent, inflammatory cells (Figure 3). The CXCR4 antagonist AMD3100, also known as Plerixafor, has been approved as mobilizer of hematopoietic stem cells in combination with G-CSF in treatment of patients with nonHodgkin's lymphoma and multiple myeloma, and many other small molecule inhibitors of CXCR4 are in clinical trial or under investigation (Debnath et al., 2013). However, a potential future application of such inhibitors in treatment of patients with CAD is currently only speculative. Although mobilization of progenitor cells has been associated with cardioprotection in context of myocardial ischemia and also initial clinical trials for stem cell therapy after MI are encouraging, many important aspects of such therapy-as optimal cell type, dose, time and method of administration, long-term effects-remain to be investigated (Sanganalmath and Bolli, 2013). Furthermore, contrasting reports on the effect of AMD3100 treatment on cardiac outcome after MI warns for a further evaluation of underlying mechanisms, and also the recently revealed double-edged role of CXCR4 in myocardial ischemia necessitates a careful evaluation of drugs interfering with CXCL12/CXCR4 signaling. In addition, possible unwanted side effects need to be cautiously monitored. For example, one patient study examining the effects of progenitor cell mobilization on cardiac function after MI 


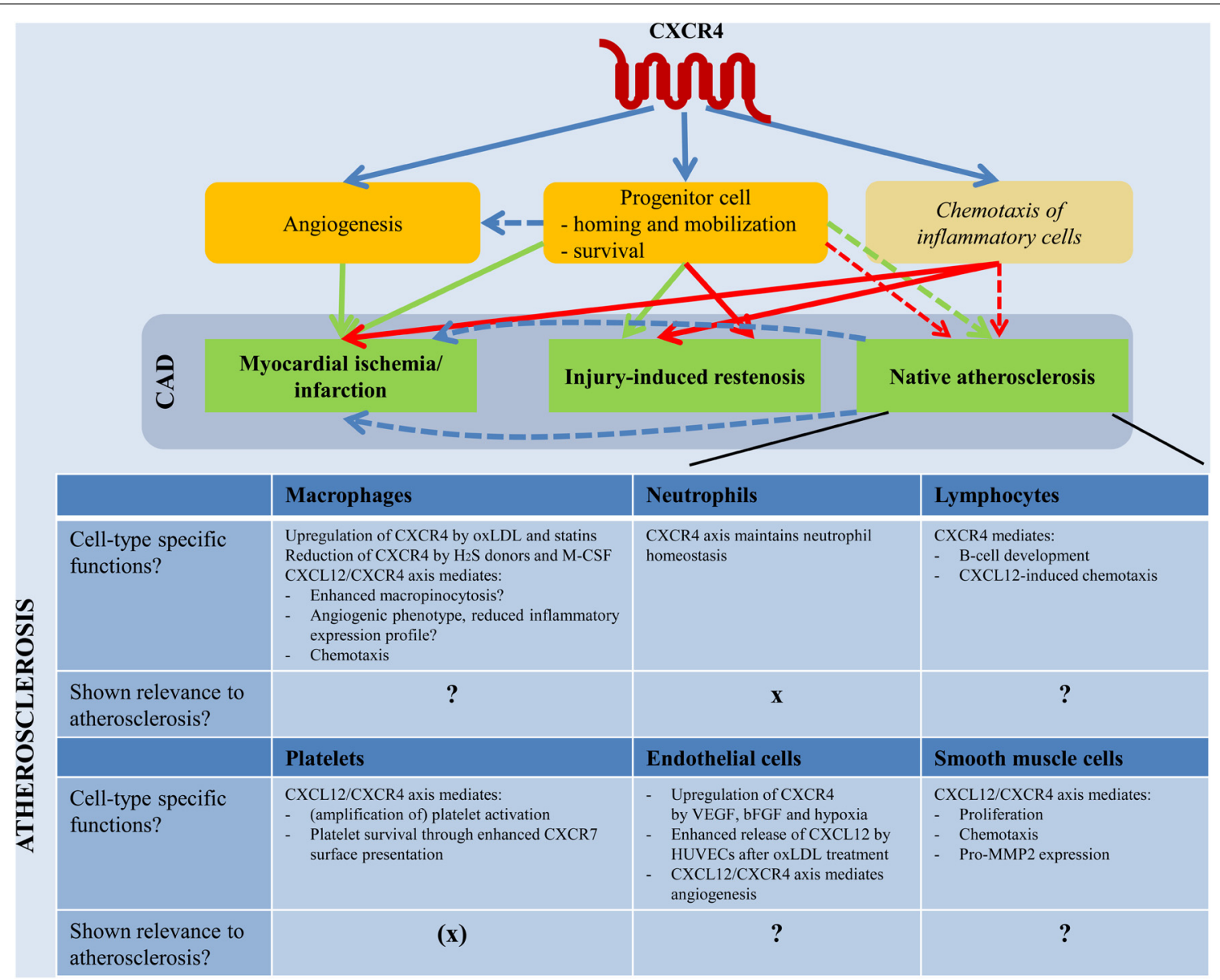

FIGURE 3 | Involvement of CXCR4 in CAD. The chemokine receptor CXCR4 plays a role in angiogenesis. Furthermore, it is an important regulator of homing, mobilization and survival of progenitor cells. This has linked CXCR4 with a role in myocardial ischemia and injury-induced restenosis, but its significance in the context of native atherosclerosis remains unclear. CXCR4 has also been reported to mediate leukocyte chemotaxis in specific inflammatory diseases. A similar role in inflammatory cell recruitment has been suggested in the context of myocardial ischemia, but the importance of CXCR4-induced leukocyte recruitment to atherosclerotic lesions in vivo remains to be further addressed. The current view mainly emphasizes the involvement of inflammatory chemokines instead of the homeostatic chemokine CXCL12 in mediating atherogenic leukocyte recruitment. However, CXCR4 can mediate both CXCL12- and MIF-induced chemotaxis of
B- and T-cells in vitro, and is also expressed on a subset of monocytes, requiring further research of its function in atherogenic leukocyte recruitment in vivo. Also, it remains unclear which cell type-specific functions of CXCR4 may be important in context of atherosclerosis, with currently only scarce information on potential cellular functions in most cell types present in atherosclerotic lesions. For more details, we refer to the text. Green arrows indicate beneficial effects, red arrows indicate detrimental effects. The interrelation between different pathologies belonging to CAD is visualized. The lower panels indicate relevance of CXCR4-involving cell type-specific functions to atherosclerotic plaque formation. bFGF, basic fibroblast growth factor; CAD, coronary artery disease; H2S, hydrogen sulfide; M-CSF, macrophage colony stimulating factor; MMP, matrix metallopeptidase; oxLDL, oxidized low-density lipoprotein; VEGF, vascular endothelial growth factor. was terminated early due to enhanced in-stent restenosis (Kang et al., 2004). Also, a closer investigation of the effect of CXCR4 antagonists on progenitor cell mobilization in context of different cardiovascular disease settings or upon different dosage or administration methods seems interesting, as contrasting findings were reported on the effect of continuous administration of the CXCR4 antagonist AMD3465 on the mobilization of $\mathrm{Lin}^{-} \mathrm{Scal}^{+}$cells in context of native atherosclerosis $v s$ injuryinduced restenosis (Karshovska et al., 2008; Zernecke et al., 2008).

Furthermore, additional studies are required to unravel in more detail the cellular processes in which CXCR4 is involved and the underlying molecular mechanisms. In this context, complexness of CXCR4-associated biological and mechanistic aspects is significantly being increased by the identification of MIF as a secondary chemokine ligand for CXCR4, and of CXCR7 as an alternative receptor for CXCL12. Intertwining of chemokine receptor signaling may enhance fine tuning and optimization of leukocyte chemotaxis in physiological conditions. In addition, it may increase the possibilities for designing therapeutics interfering with only selective aspects of chemokine signaling, for example by targeting chemokine receptor heterodimerization (Koenen and Weber, 2010). But again, this necessitates a better understanding of biological and mechanistic aspects of all involved chemokine ligand/receptor axes and their interplay. 


\section{ACKNOWLEDGMENTS}

This work was supported by the German Research Foundation (DFG FOR809 to Christian Weber), the European Research Council (ERC AdG 249929 to Christian Weber), the Fondation Leducq (to Christian Weber), the START Program of the Faculty of Medicine, RWTH Aachen (49/13 to Heidi Noels), and the German Heart Foundation/German Foundation of Heart Research (F/40/12 to Heidi Noels). We thank Dr. med. E. Liehn, Prof. J. Bernhagen and Prof N. Marx for their support, and sincerely apologize to all scientists whose important contributions to the field could not be cited due to space limitations.

\section{SUPPLEMENTARY MATERIAL}

The Supplementary Material for this article can be found online at: http://www.frontiersin.org/journal/10.3389/fphys.2014. 00212/abstract

\section{REFERENCES}

Abbott, J. D., Huang, Y., Liu, D., Hickey, R., Krause, D. S., and Giordano, F. J. (2004). Stromal cell-derived factor-lalpha plays a critical role in stem cell recruitment to the heart after myocardial infarction but is not sufficient to induce homing in the absence of injury. Circulation 110, 3300-3305. doi: 10.1161/01.CIR.0000147780.30124.CF

Abi-Younes, S., Sauty, A., Mach, F., Sukhova, G. K., Libby, P., and Luster, A. D. (2000). The stromal cell-derived factor- 1 chemokine is a potent platelet agonist highly expressed in atherosclerotic plaques. Circ. Res. 86, 131-138. doi: 10.1161/01.RES.86.2.131

Agarwal, U., Ghalayini, W., Dong, F., Weber, K., Zou, Y. R., Rabbany, S. Y., et al. (2010). Role of cardiac myocyte CXCR4 expression in development and left ventricular remodeling after acute myocardial infarction. Circ. Res. 107, 667-676. doi: 10.1161/CIRCRESAHA.110.223289

Aird, W. C. (2007). Phenotypic heterogeneity of the endothelium: I. Structure, function, and mechanisms. Circ. Res. 100, 158-173. doi: 10.1161/01.RES.0000255691.76142.4a

Akhtar, S., Gremse, F., Kiessling, F., Weber, C., and Schober, A. (2013). CXCL12 promotes the stabilization of atherosclerotic lesions mediated by smooth muscle progenitor cells in Apoe-deficient mice. Arterioscler. Thromb. Vasc. Biol. 33, 679-686. doi: 10.1161/ATVBAHA.112.301162

Apostolakis, S., Krambovitis, E., Vlata, Z., Kochiadakis, G. E., Baritaki, S., and Spandidos, D. A. (2007). CX3CR1 receptor is up-regulated in monocytes of coronary artery diseased patients: impact of pre-inflammatory stimuli and renin-angiotensin system modulators. Thromb. Res. 121, 387-395. doi: 10.1016/j.thromres.2007.04.005

Apostolakis, S., Vlata, Z., Vogiatzi, K., Krambovitis, E., and Spandidos, D. A. (2010). Angiotensin II up-regulates CX3CR1 expression in THP-1 monocytes: impact on vascular inflammation and atherogenesis. J. Thromb. Thrombolysis 29, 443-448. doi: 10.1007/s11239-009-0424-1

Ara, T., Tokoyoda, K., Okamoto, R., Koni, P. A., and Nagasawa, T. (2005). The role of CXCL12 in the organ-specific process of artery formation. Blood 105, 3155-3161. doi: 10.1182/blood-2004-07-2563

Asare, Y., Schmitt, M., and Bernhagen, J. (2013). The vascular biology of macrophage migration inhibitory factor (MIF). Expression and effects in inflammation, atherogenesis and angiogenesis. Thromb. Haemost. 109, 391-398. doi: 10.1160/TH12-11-0831

Bachelerie, F., Ben-Baruch, A., Burkhardt, A. M., Combadiere, C., Farber, J. M., Graham, G. J., et al. (2014). International Union of Pharmacology. LXXXIX. Update on the extended family of chemokine receptors and introducing a new nomenclature for atypical chemokine receptors. Pharmacol. Rev. 66, 1-79. doi: 10.1124/pr.113.007724

Balabanian, K., Lagane, B., Infantino, S., Chow, K. Y., Harriague, J., Moepps, B., et al. (2005). The chemokine SDF-1/CXCL12 binds to and signals through the orphan receptor RDC1 in T lymphocytes. J. Biol. Chem. 280, 35760-35766. doi: 10.1074/jbc.M508234200
Basu, S., and Broxmeyer, H. E. (2005). Transforming growth factor-\{beta\}1 modulates responses of $\mathrm{CD} 34+$ cord blood cells to stromal cell-derived factor1/CXCL12. Blood 106, 485-493. doi: 10.1182/blood-2004-10-4145

Basu, S., and Broxmeyer, H. E. (2009). CCR5 ligands modulate CXCL12-induced chemotaxis, adhesion, and Akt phosphorylation of human cord blood CD34+ cells. J. Immunol. 183, 7478-7488. doi: 10.4049/jimmunol.0900542

Bernhagen, J., Krohn, R., Lue, H., Gregory, J. L., Zernecke, A., Koenen, R. R., et al. (2007). MIF is a noncognate ligand of CXC chemokine receptors in inflammatory and atherogenic cell recruitment. Nat. Med. 13, 587-596. doi: $10.1038 / \mathrm{nm} 1567$

Bernhagen, J., Mitchell, R. A., Calandra, T., Voelter, W., Cerami, A., and Bucala, R. (1994). Purification, bioactivity, and secondary structure analysis of mouse and human macrophage migration inhibitory factor (MIF). Biochemistry 33, 14144-14155. doi: 10.1021/bi00251a025

Blanchet, X., Langer, M., Weber, C., Koenen, R. R., and Von Hundelshausen, P. (2012). Touch of chemokines. Front. Immunol. 3:175. doi: 10.3389/fimmu.2012.00175

Bleul, C. C., Farzan, M., Choe, H., Parolin, C., Clark-Lewis, I., Sodroski, J., et al. (1996a). The lymphocyte chemoattractant SDF-1 is a ligand for LESTR/fusin and blocks HIV-1 entry. Nature 382, 829-833. doi: 10.1038/382829a0

Bleul, C. C., Fuhlbrigge, R. C., Casasnovas, J. M., Aiuti, A., and Springer, T. A. (1996b). A highly efficacious lymphocyte chemoattractant, stromal cell-derived factor 1 (SDF-1). J. Exp. Med. 184, 1101-1109. doi: 10.1084/jem.184.3.1101

Bonig, H., and Papayannopoulou, T. (2012). Mobilization of hematopoietic stem/progenitor cells: general principles and molecular mechanisms. Methods Mol. Biol. 904, 1-14. doi: 10.1007/978-1-61779-943-3_1

Bosch, J. A., Berntson, G. G., Cacioppo, J. T., Dhabhar, F. S., and Marucha, P. T. (2003). Acute stress evokes selective mobilization of T cells that differ in chemokine receptor expression: a potential pathway linking immunologic reactivity to cardiovascular disease. Brain Behav. Immun. 17, 251-259. doi: 10.1016/S0889-1591(03)00054-0

Broxmeyer, H. E., Cooper, S., Kohli, L., Hangoc, G., Lee, Y., Mantel, C., et al. (2003a). Transgenic expression of stromal cell-derived factor-1/CXC chemokine ligand 12 enhances myeloid progenitor cell survival/antiapoptosis in vitro in response to growth factor withdrawal and enhances myelopoiesis in vivo. J. Immunol. 170, 421-429. doi: 10.4049/jimmunol.170.1.421

Broxmeyer, H. E., Kohli, L., Kim, C. H., Lee, Y., Mantel, C., Cooper, S., et al. (2003b). Stromal cell-derived factor-1/CXCL12 directly enhances survival/antiapoptosis of myeloid progenitor cells through CXCR4 and G(alpha)i proteins and enhances engraftment of competitive, repopulating stem cells. J. Leukoc. Biol. 73, 630-638. doi: 10.1189/jlb.1002495

Bruhl, H., Cohen, C. D., Linder, S., Kretzler, M., Schlondorff, D., and Mack, M. (2003). Post-translational and cell type-specific regulation of CXCR 4 expression by cytokines. Eur. J. Immunol. 33, 3028-3037. doi: 10.1002/eji.200324163

Burns, J. M., Summers, B. C., Wang, Y., Melikian, A., Berahovich, R., Miao, Z., et al. (2006). A novel chemokine receptor for SDF-1 and I-TAC involved in cell survival, cell adhesion, and tumor development. J. Exp. Med. 203, 2201-2213. doi: $10.1084 /$ jem.20052144

Burton, P. R., Clayton, D. G., Cardon, L. R., Craddock, N., Deloukas, P., Duncanson, A., et al. (2007). The Wellcome Trust Case Control Consortium. Genome-wide association study of 14,000 cases of seven common diseases and 3,000 shared controls. Nature 447, 661-678. doi: 10.1038/nature05911

Camnitz, W., Burdick, M. D., Strieter, R. M., Mehrad, B., and Keeley, E. C. (2012). Dose-dependent Effect of Statin Therapy on Circulating CXCL12 Levels in Patients with Hyperlipidemia. Clin. Transl. Med. 1:23. doi: 10.1186/20011326-1-23

Campbell, T. B., and Broxmeyer, H. E. (2008). CD26 inhibition and hematopoiesis: a novel approach to enhance transplantation. Front. Biosci. 13, 1795-1805. doi: $10.2741 / 2800$

Caulfield, J., Fernandez, M., Snetkov, V., Lee, T., and Hawrylowicz, C. (2002). CXCR4 expression on monocytes is up-regulated by dexamethasone and is modulated by autologous $\mathrm{CD} 3+\mathrm{T}$ cells. Immunology 105, 155-162. doi: 10.1046/j.0019-2805.2001.01359.x

Ceradini, D. J., Kulkarni, A. R., Callaghan, M. J., Tepper, O. M., Bastidas, N., Kleinman, M. E., et al. (2004). Progenitor cell trafficking is regulated by hypoxic gradients through HIF-1 induction of SDF-1. Nat. Med. 10, 858-864. doi: $10.1038 / \mathrm{nm} 1075$

Chatterjee, M., Seizer, P., Borst, O., Schonberger, T., Mack, A., Geisler, T., et al. (2014). SDF-1alpha induces differential trafficking of CXCR4-CXCR7 involving 
cyclophilin A, CXCR7 ubiquitination and promotes platelet survival. FASEB J. 28. doi: 10.1096/fj.14-249730. [Epub ahead of print].

Chen, J., Chemaly, E., Liang, L., Kho, C., Lee, A., Park, J., et al. (2010a). Effects of CXCR4 gene transfer on cardiac function after ischemia-reperfusion injury. Am. J. Pathol. 176, 1705-1715. doi: 10.2353/ajpath.2010.090451

Chen, L., Wu, F., Xia, W. H., Zhang, Y. Y., Xu, S. Y., Cheng, F., et al. (2010b). CXCR4 gene transfer contributes to in vivo reendothelialization capacity of endothelial progenitor cells. Cardiovasc. Res. 88, 462-470. doi: 10.1093/cvr/cvq207

Cheng, Q., Mckeown, S. J., Santos, L., Santiago, F. S., Khachigian, L. M., Morand, E. F., et al. (2010). Macrophage migration inhibitory factor increases leukocyteendothelial interactions in human endothelial cells via promotion of expression of adhesion molecules. J. Immunol. 185, 1238-1247. doi: 10.4049/jimmunol.0904104

Christopherson, K. W. 2nd., Cooper, S., and Broxmeyer, H. E. (2003a). Cell surface peptidase CD26/DPPIV mediates G-CSF mobilization of mouse progenitor cells. Blood 101, 4680-4686. doi: 10.1182/blood-2002-12-3893

Christopherson, K. W., Cooper, S., Hangoc, G., and Broxmeyer, H. E. (2003b). CD26 is essential for normal G-CSF-induced progenitor cell mobilization as determined by CD26-/- mice. Exp. Hematol. 31, 1126-1134. doi: 10.1016/j.exphem.2003.07.002

Chu, P. Y., Zatta, A., Kiriazis, H., Chin-Dusting, J., Du, X. J., Marshall, T., et al. (2011). CXCR4 antagonism attenuates the cardiorenal consequences of mineralocorticoid excess. Circ. Heart Fail. 4, 651-658. doi: 10.1161/CIRCHEARTFAILURE.110.960831

Dai, S., Yuan, F., Mu, J., Li, C., Chen, N., Guo, S., et al. (2010). Chronic AMD3100 antagonism of SDF-1alpha-CXCR4 exacerbates cardiac dysfunction and remodeling after myocardial infarction. J. Mol. Cell. Cardiol. 49, 587-597. doi: 10.1016/j.yjmcc.2010.07.010

Damas, J. K., Waehre, T., Yndestad, A., Ueland, T., Muller, F., Eiken, H. G., et al. (2002). Stromal cell-derived factor-1alpha in unstable angina: potential antiinflammatory and matrix-stabilizing effects. Circulation 106, 36-42. doi: 10.1161/01.CIR.0000020001.09990.90

Dar, A., Schajnovitz, A., Lapid, K., Kalinkovich, A., Itkin, T., Ludin, A., et al. (2011). Rapid mobilization of hematopoietic progenitors by AMD3100 and catecholamines is mediated by CXCR4-dependent SDF-1 release from bone marrow stromal cells. Leukemia 25, 1286-1296. doi: 10.1038/leu.2011.62

Debnath, B., Xu, S., Grande, F., Garofalo, A., and Neamati, N. (2013). Small molecule inhibitors of CXCR4. Theranostics 3, 47-75. doi: 10.7150/thno. 5376

Decaillot, F. M., Kazmi, M. A., Lin, Y., Ray-Saha, S., Sakmar, T. P., and Sachdev, P. (2011). CXCR7/CXCR4 heterodimer constitutively recruits betaarrestin to enhance cell migration. J. Biol. Chem. 286, 32188-32197. doi: 10.1074/jbc.M111.277038

De Clercq, E. (2000). Inhibition of HIV infection by bicyclams, highly potent and specific CXCR4 antagonists. Mol. Pharmacol. 57, 833-839.

De Gaetano, M., Dempsey, E., Marcone, S., James, W. G., and Belton, O. (2013). Conjugated linoleic acid targets beta2 integrin expression to suppress monocyte adhesion. J. Immunol. 191, 4326-4336. doi: 10.4049/jimmunol.1300990

Dela Paz, N. G., and D'amore, P. A. (2009). Arterial versus venous endothelial cells. Cell Tissue Res. 335, 5-16. doi: 10.1007/s00441-008-0706-5

Di Stefano, R., Felice, F., and Balbarini, A. (2009). Angiogenesis as risk factor for plaque vulnerability. Curr. Pharm. Des. 15, 1095-1106. doi: $10.2174 / 138161209787846892$

Domanska, U. M., Kruizinga, R. C., Nagengast, W. B., Timmer-Bosscha, H., Huls, G., De Vries, E. G., et al. (2013). A review on CXCR4/CXCL12 axis in oncology: no place to hide. Eur. J. Cancer 49, 219-230. doi: 10.1016/j.ejca.2012.05.005

Dong, F., Harvey, J., Finan, A., Weber, K., Agarwal, U., and Penn, M. S. (2012). Myocardial CXCR4 expression is required for mesenchymal stem cell mediated repair following acute myocardial infarction. Circulation 126, 314-324. doi: 10.1161/CIRCULATIONAHA.111.082453

Doring, Y., Soehnlein, O., Drechsler, M., Shagdarsuren, E., Chaudhari, S. M., Meiler, S., et al. (2012). Hematopoietic interferon regulatory factor 8deficiency accelerates atherosclerosis in mice. Arterioscler. Thromb. Vasc. Biol. 32, 1613-1623. doi: 10.1161/ATVBAHA.111.236539

Drechsler, M., Doring, Y., Megens, R. T., and Soehnlein, O. (2011). Neutrophilic granulocytes - promiscuous accelerators of atherosclerosis. Thromb. Haemost. 106, 839-848. doi: 10.1160/TH11-07-0501

Drechsler, M., Megens, R. T., Van Zandvoort, M., Weber, C., and Soehnlein, O. (2010). Hyperlipidemia-triggered neutrophilia promotes early atherosclerosis. Circulation 122, 1837-1845. doi: 10.1161/CIRCULATIONAHA.110.961714
Drury, L. J., Ziarek, J. J., Gravel, S., Veldkamp, C. T., Takekoshi, T., Hwang, S. T., et al. (2011). Monomeric and dimeric CXCL12 inhibit metastasis through distinct CXCR4 interactions and signaling pathways. Proc. Natl. Acad. Sci. U.S.A. 108, 17655-17660. doi: 10.1073/pnas.1101133108

Du, F., Zhou, J., Gong, R., Huang, X., Pansuria, M., Virtue, A., et al. (2012). Endothelial progenitor cells in atherosclerosis. Front. Biosci. (Landmark Ed.) 17, 2327-2349. doi: 10.2741/4055

Dunussi-Joannopoulos, K., Zuberek, K., Runyon, K., Hawley, R. G., Wong, A., Erickson, J., et al. (2002). Efficacious immunomodulatory activity of the chemokine stromal cell-derived factor 1 (SDF-1): local secretion of SDF-1 at the tumor site serves as T-cell chemoattractant and mediates T-cell-dependent antitumor responses. Blood 100, 1551-1558.

Dutta, P., Courties, G., Wei, Y., Leuschner, F., Gorbatov, R., Robbins, C. S., et al. (2012). Myocardial infarction accelerates atherosclerosis. Nature 487, 325-329. doi: 10.1038/nature11260

Eash, K. J., Means, J. M., White, D. W., and Link, D. C. (2009). CXCR4 is a key regulator of neutrophil release from the bone marrow under basal and stress granulopoiesis conditions. Blood 113, 4711-4719. doi: 10.1182/blood-2008-09177287

Elmadbouh, I., Haider, H., Jiang, S., Idris, N. M., Lu, G., and Ashraf, M. (2007). Ex vivo delivered stromal cell-derived factor-1alpha promotes stem cell homing and induces angiomyogenesis in the infarcted myocardium. J. Mol. Cell. Cardiol. 42, 792-803. doi: 10.1016/j.yjmcc.2007.02.001

Eugenin, E. A., Morgello, S., Klotman, M. E., Mosoian, A., Lento, P. A., Berman, J. W., et al. (2008). Human immunodeficiency virus (HIV) infects human arterial smooth muscle cells in vivo and in vitro: implications for the pathogenesis of HIV-mediated vascular disease. Am. J. Pathol. 172, 1100-1111. doi: 10.2353/ajpath.2008.070457

Falk, E., Shah, P. K., and Fuster, V. (1995). Coronary plaque disruption. Circulation 92, 657-671. doi: 10.1161/01.CIR.92.3.657

Farouk, S. S., Rader, D. J., Reilly, M. P., and Mehta, N. N. (2010). CXCL12: a new player in coronary disease identified through human genetics. Trends Cardiovasc. Med. 20, 204-209. doi: 10.1016/j.tcm.2011.08.002

Feil, C., and Augustin, H. G. (1998). Endothelial cells differentially express functional CXC-chemokine receptor-4 (CXCR-4/fusin) under the control of autocrine activity and exogenous cytokines. Biochem. Biophys. Res. Commun. 247, 38-45. doi: 10.1006/bbrc.1998.8499

Fernandis, A. Z., Cherla, R. P., and Ganju, R. K. (2003). Differential regulation of CXCR4-mediated T-cell chemotaxis and mitogen-activated protein kinase activation by the membrane tyrosine phosphatase, CD45. J. Biol. Chem. 278, 9536-9543. doi: 10.1074/jbc.M211803200

Fukuda, S., Broxmeyer, H. E., and Pelus, L. M. (2005). Flt3 ligand and the Flt3 receptor regulate hematopoietic cell migration by modulating the SDF1alpha(CXCL12)/CXCR4 axis. Blood 105, 3117-3126. doi: 10.1182/blood-2004$04-1440$

Gao, X. M., Liu, Y., White, D., Su, Y., Drew, B. G., Bruce, C. R., et al. (2011). Deletion of macrophage migration inhibitory factor protects the heart from severe ischemia-reperfusion injury: a predominant role of antiinflammation. J. Mol. Cell. Cardiol. 50, 991-999. doi: 10.1016/j.yjmcc. 2010.12.022

Gear, A. R., Suttitanamongkol, S., Viisoreanu, D., Polanowska-Grabowska, R. K., Raha, S., and Camerini, D. (2001). Adenosine diphosphate strongly potentiates the ability of the chemokines MDC, TARC, and SDF-1 to stimulate platelet function. Blood 97, 937-945. doi: 10.1182/blood.V97.4.937

George, J., Afek, A., Abashidze, A., Shmilovich, H., Deutsch, V., Kopolovich, J., et al. (2005). Transfer of endothelial progenitor and bone marrow cells influences atherosclerotic plaque size and composition in apolipoprotein E knockout mice. Arterioscler. Thromb. Vasc. Biol. 25, 2636-2641. doi: 10.1161/01.ATV.0000188554.49745.9e

Gomez, D., and Owens, G. K. (2012). Smooth muscle cell phenotypic switching in atherosclerosis. Cardiovasc. Res. 95, 156-164. doi: 10.1093/cvr/cvs115

Gravel, S., Malouf, C., Boulais, P. E., Berchiche, Y. A., Oishi, S., Fujii, N., et al. (2010). The peptidomimetic CXCR4 antagonist TC14012 recruits beta-arrestin to CXCR7: roles of receptor domains. J. Biol. Chem. 285, 37939-37943. doi: $10.1074 /$ jbc.C110.147470

Guo, Y., Hangoc, G., Bian, H., Pelus, L. M., and Broxmeyer, H. E. (2005). SDF1/CXCL12 enhances survival and chemotaxis of murine embryonic stem cells and production of primitive and definitive hematopoietic progenitor cells. Stem Cells 23, 1324-1332. doi: 10.1634/stemcells.2005-0085 
Gupta, S. K., Lysko, P. G., Pillarisetti, K., Ohlstein, E., and Stadel, J. M. (1998). Chemokine receptors in human endothelial cells. Functional expression of CXCR4 and its transcriptional regulation by inflammatory cytokines. J. Biol. Chem. 273, 4282-4287. doi: 10.1074/jbc.273.7.4282

Gupta, S. K., Pillarisetti, K., and Lysko, P. G. (1999). Modulation of CXCR4 expression and SDF-1alpha functional activity during differentiation of human monocytes and macrophages. J. Leukoc. Biol. 66, 135-143.

Hagensen, M. K., Raarup, M. K., Mortensen, M. B., Thim, T., Nyengaard, J. R., Falk, E., et al. (2012). Circulating endothelial progenitor cells do not contribute to regeneration of endothelium after murine arterial injury. Cardiovasc. Res. 93, 223-231. doi: 10.1093/cvr/cvr278

Hamesch, K., Subramanian, P., Li, X., Dembowsky, K., Chevalier, E., Weber, C., et al. (2012). The CXCR4 antagonist POL5551 is equally effective as sirolimus in reducing neointima formation without impairing re-endothelialisation. Thromb. Haemost. 107, 356-368. doi: 10.1160/TH11-07-0453

Han, K. H., Hong, K. H., Ko, J., Rhee, K. S., Hong, M. K., Kim, J. J., et al. (2004). Lysophosphatidylcholine up-regulates CXCR4 chemokine receptor expression in human CD4 T cells. J. Leukoc. Biol. 76, 195-202. doi: 10.1189/jlb.1103563

Hansson, G. K., and Hermansson, A. (2011). The immune system in atherosclerosis. Nat. Immunol. 12, 204-212. doi: 10.1038/ni.2001

Hara, Y., Kusumi, Y., Mitsumata, M., Li, X. K., and Fujino, M. (2008). Lysophosphatidylcholine upregulates LOX-1, chemokine receptors, and activation-related transcription factors in human T-cell line Jurkat. J. Thromb. Thrombolysis 26, 113-118. doi: 10.1007/s11239-007-0158-x

Hatse, S., Princen, K., De Clercq, E., Rosenkilde, M. M., Schwartz, T. W., Hernandez-Abad, P. E., et al. (2005). AMD3465, a monomacrocyclic CXCR4 antagonist and potent HIV entry inhibitor. Biochem. Pharmacol. 70, 752-761. doi: 10.1016/j.bcp.2005.05.035

Hattori, K., Heissig, B., Tashiro, K., Honjo, T., Tateno, M., Shieh, J. H., et al. (2001). Plasma elevation of stromal cell-derived factor-1 induces mobilization of mature and immature hematopoietic progenitor and stem cells. Blood 97, 3354-3360. doi: 10.1182/blood.V97.11.3354

Hatzistergos, K. E., Quevedo, H., Oskouei, B. N., Hu, Q., Feigenbaum, G. S., Margitich, I. S., et al. (2010). Bone marrow mesenchymal stem cells stimulate cardiac stem cell proliferation and differentiation. Circ. Res. 107, 913-922. doi: 10.1161/CIRCRESAHA.110.222703

Hillyer, P., Mordelet, E., Flynn, G., and Male, D. (2003). Chemokines, chemokine receptors and adhesion molecules on different human endothelia: discriminating the tissue-specific functions that affect leucocyte migration. Clin. Exp. Immunol. 134, 431-441. doi: 10.1111/j.1365-2249.2003.02323.x

Hirschhorn, J. N., and Daly, M. J. (2005). Genome-wide association studies for common diseases and complex traits. Nat. Rev. Genet. 6, 95-108. doi: $10.1038 / \mathrm{nrg} 1521$

Hristov, M., Zernecke, A., Bidzhekov, K., Liehn, E. A., Shagdarsuren, E., Ludwig, A., et al. (2007). Importance of CXC chemokine receptor 2 in the homing of human peripheral blood endothelial progenitor cells to sites of arterial injury. Circ. Res. 100, 590-597. doi: 10.1161/01.RES.0000259043.42571.68

Hu, X., Dai, S., Wu, W. J., Tan, W., Zhu, X., Mu, J., et al. (2007). Stromal cell derived factor-1 alpha confers protection against myocardial ischemia/reperfusion injury: role of the cardiac stromal cell derived factor-1 alpha CXCR4 axis. Circulation 116, 654-663. doi: 10.1161/CIRCULATIONAHA.106.672451

Huang, W., Wang, T., Zhang, D., Zhao, T., Dai, B., Ashraf, A., et al. (2012). Mesenchymal stem cells overexpressing CXCR4 attenuate remodeling of postmyocardial infarction by releasing matrix metalloproteinase-9. Stem Cells Dev. 21, 778-789. doi: 10.1089/scd.2011.0126

Ingersoll, M. A., Spanbroek, R., Lottaz, C., Gautier, E. L., Frankenberger, M., Hoffmann, R., et al. (2010). Comparison of gene expression profiles between human and mouse monocyte subsets. Blood 115, e10-e19. doi: 10.1182/blood2009-07-235028

Irvine, K. M., Andrews, M. R., Fernandez-Rojo, M. A., Schroder, K., Burns, C. J., Su, S., et al. (2009). Colony-stimulating factor-1 (CSF-1) delivers a proatherogenic signal to human macrophages. J. Leukoc. Biol. 85, 278-288. doi: 10.1189/jlb.0808497

Iwata, H., Manabe, I., Fujiu, K., Yamamoto, T., Takeda, N., Eguchi, K., et al. (2010). Bone marrow-derived cells contribute to vascular inflammation but do not differentiate into smooth muscle cell lineages. Circulation 122, 2048-2057. doi: 10.1161/CIRCULATIONAHA.110.965202

Jabs, A., Okamoto, E., Vinten-Johansen, J., Bauriedel, G., and Wilcox, J. N. (2007). Sequential patterns of chemokine- and chemokine receptor-synthesis following vessel wall injury in porcine coronary arteries. Atherosclerosis 192, 75-84. doi: 10.1016/j.atherosclerosis.2006.05.050

Jaipersad, A. S., Shantsila, E., Blann, A., and Lip, G. Y. (2013). The effect of statin therapy withdrawal on monocyte subsets. Eur. J. Clin. Invest. 43, 1307-1313. doi: $10.1111 /$ eci.12183

Jie, W., Wang, X., Zhang, Y., Guo, J., Kuang, D., Zhu, P., et al. (2010). SDFlalpha/CXCR4 axis is involved in glucose-potentiated proliferation and chemotaxis in rat vascular smooth muscle cells. Int. J. Exp. Pathol. 91, 436-444. doi: 10.1111/j.1365-2613.2010.00720.x

Jin, F., Brockmeier, U., Otterbach, F., and Metzen, E. (2012). New insight into the SDF-1/CXCR4 axis in a breast carcinoma model: hypoxia-induced endothelial SDF-1 and tumor cell CXCR4 are required for tumor cell intravasation. Mol. Cancer Res. 10, 1021-1031. doi: 10.1158/1541-7786.MCR-11-0498

Jones, D. L., and Wagers, A. J. (2008). No place like home: anatomy and function of the stem cell niche. Nat. Rev. Mol. Cell Biol. 9, 11-21. doi: 10.1038/nrm2319

Jujo, K., Hamada, H., Iwakura, A., Thorne, T., Sekiguchi, H., Clarke, T., et al. (2010). CXCR4 blockade augments bone marrow progenitor cell recruitment to the neovasculature and reduces mortality after myocardial infarction. Proc. Natl. Acad. Sci. U.S.A. 107, 11008-11013. doi: 10.1073/pnas.0914248107

Jujo, K., Ii, M., Sekiguchi, H., Klyachko, E., Misener, S., Tanaka, T., et al. (2013). CXC-chemokine receptor 4 antagonist AMD3100 promotes cardiac functional recovery after ischemia/reperfusion injury via endothelial nitric oxide synthase-dependent mechanism. Circulation 127, 63-73. doi: 10.1161/CIRCULATIONAHA.112.099242

Kalatskaya, I., Berchiche, Y. A., Gravel, S., Limberg, B. J., Rosenbaum, J. S., and Heveker, N. (2009). AMD3100 is a CXCR7 ligand with allosteric agonist properties. Mol. Pharmacol. 75, 1240-1247. doi: 10.1124/mol.108.053389

Kang, H. J., Kim, H. S., Zhang, S. Y., Park, K. W., Cho, H. J., Koo, B. K., et al. (2004). Effects of intracoronary infusion of peripheral blood stem-cells mobilised with granulocyte-colony stimulating factor on left ventricular systolic function and restenosis after coronary stenting in myocardial infarction: the MAGIC cell randomised clinical trial. Lancet 363, 751-756. doi: 10.1016/S01406736(04)15689-4

Kanzler, I., Tuchscheerer, N., Steffens, G., Simsekyilmaz, S., Konschalla, S., Kroh, A., et al. (2013). Differential roles of angiogenic chemokines in endothelial progenitor cell-induced angiogenesis. Basic Res. Cardiol. 108:310. doi: 10.1007/s00395-012-0310-4

Karpova, D., Dauber, K., Spohn, G., Chudziak, D., Wiercinska, E., Schulz, M., et al. (2013). The novel CXCR4 antagonist POL5551 mobilizes hematopoietic stem and progenitor cells with greater efficiency than Plerixafor. Leukemia 27, 2322-2331. doi: 10.1038/leu.2013.266

Karshovska, E., Zagorac, D., Zernecke, A., Weber, C., and Schober, A. (2008). A small molecule CXCR4 antagonist inhibits neointima formation and smooth muscle progenitor cell mobilization after arterial injury. J. Thromb. Haemost. 6, 1812-1815. doi: 10.1111/j.1538-7836.2008.03086.x

Karshovska, E., Zernecke, A., Sevilmis, G., Millet, A., Hristov, M., Cohen, C. D., et al. (2007). Expression of HIF-1alpha in injured arteries controls SDFlalpha mediated neointima formation in apolipoprotein E deficient mice. Arterioscler. Thromb. Vasc. Biol. 27, 2540-2547. doi: 10.1161/ATVBAHA.107. 151050

Kathiresan, S., Voight, B. F., Purcell, S., Musunuru, K., Ardissino, D., Mannucci, P. M., et al. (2009). Genome-wide association of early-onset myocardial infarction with single nucleotide polymorphisms and copy number variants. Nat. Genet. 41, 334-341. doi: 10.1038/ng.327

Kiechl, S., Laxton, R. C., Xiao, Q., Hernesniemi, J. A., Raitakari, O. T., Kahonen, M., et al. (2010). Coronary artery disease-related genetic variant on chromosome $10 \mathrm{q} 11$ is associated with carotid intima-media thickness and atherosclerosis. Arterioscler. Thromb. Vasc. Biol. 30, 2678-2683. doi: 10.1161/ATVBAHA.110.213785

Klasen, C., Ohl, K., Sternkopf, M., Shachar, I., Schmitz, C., Heussen, N., et al. (2014). MIF Promotes B cell chemotaxis through the receptors CXCR4 and CD74 and ZAP-70 signaling. J. Immunol. 192, 5273-5284. doi: 10.4049/ jimmunol.1302209

Kodali, R., Hajjou, M., Berman, A. B., Bansal, M. B., Zhang, S., Pan, J. J., et al. (2006). Chemokines induce matrix metalloproteinase-2 through activation of epidermal growth factor receptor in arterial smooth muscle cells. Cardiovasc. Res. 69, 706-715. doi: 10.1016/j.cardiores.2005.09.012

Koenen, R. R., and Weber, C. (2010). Therapeutic targeting of chemokine interactions in atherosclerosis. Nat. Rev. Drug Discov. 9, 141-153. doi: 10.1038/nrd3048 
Koga, K., Kenessey, A., Powell, S. R., Sison, C. P., Miller, E. J., and Ojamaa, K. (2011). Macrophage migration inhibitory factor provides cardioprotection during ischemia/reperfusion by reducing oxidative stress. Antioxid. Redox Signal. 14, 1191-1202. doi: 10.1089/ars.2010.3163

Kong, D., Melo, L. G., Gnecchi, M., Zhang, L., Mostoslavsky, G., Liew, C. C., et al. (2004). Cytokine-induced mobilization of circulating endothelial progenitor cells enhances repair of injured arteries. Circulation 110, 2039-2046. doi: 10.1161/01.CIR.0000143161.01901.BD

Kowalska, M. A., Ratajczak, J., Hoxie, J., Brass, L. F., Gewirtz, A., Poncz, M., et al. (1999). Megakaryocyte precursors, megakaryocytes and platelets express the HIV co-receptor CXCR4 on their surface: determination of response to stromalderived factor-1 by megakaryocytes and platelets. Br. J. Haematol. 104, 220-229. doi: 10.1046/j.1365-2141.1999.01169.x

Kraemer, B. F., Borst, O., Gehring, E. M., Schoenberger, T., Urban, B., Ninci, E., et al. (2010). PI3 kinase-dependent stimulation of platelet migration by stromal cell-derived factor 1 (SDF-1). J. Mol. Med. 88, 1277-1288. doi: 10.1007/s00109010-0680-8

Kumar, R., Tripathi, V., Ahmad, M., Nath, N., Mir, R. A., Chauhan, S. S., et al. (2012). CXCR7 mediated Gialpha independent activation of ERK and Akt promotes cell survival and chemotaxis in T cells. Cell. Immunol. 272, 230-241. doi: 10.1016/j.cellimm.2011.09.015

Larocca, T. J., Schwarzkopf, M., Altman, P., Zhang, S., Gupta, A., Gomes, I., et al (2010). beta2-Adrenergic receptor signaling in the cardiac myocyte is modulated by interactions with CXCR4. J. Cardiovasc. Pharmacol. 56, 548-559. doi: 10.1097/FJC.0b013e3181f713fe

Lataillade, J. J., Clay, D., Dupuy, C., Rigal, S., Jasmin, C., Bourin, P., et al. (2000). Chemokine SDF-1 enhances circulating CD34(+) cell proliferation in synergy with cytokines: possible role in progenitor survival. Blood 95, 756-768.

Lee, Y., Gotoh, A., Kwon, H. J., You, M., Kohli, L., Mantel, C., et al. (2002). Enhancement of intracellular signaling associated with hematopoietic progenitor cell survival in response to SDF-1/CXCL12 in synergy with other cytokines. Blood 99, 4307-4317. doi: 10.1182/blood.V99.12.4307

Levesque, J. P., Hendy, J., Takamatsu, Y., Simmons, P. J., and Bendall, L. J. (2003). Disruption of the CXCR4/CXCL12 chemotactic interaction during hematopoietic stem cell mobilization induced by GCSF or cyclophosphamide. J. Clin. Invest. 111, 187-196. doi: 10.1172/JCI15994

Levesque, J. P., Hendy, J., Takamatsu, Y., Williams, B., Winkler, I. G., and Simmons, P. J. (2002). Mobilization by either cyclophosphamide or granulocyte colony-stimulating factor transforms the bone marrow into a highly proteolytic environment. Exp. Hematol. 30, 440-449. doi: 10.1016/S0301-472X(02) 00788-9

Levesque, J. P., Liu, F., Simmons, P. J., Betsuyaku, T., Senior, R. M., Pham, C., et al. (2004). Characterization of hematopoietic progenitor mobilization in proteasedeficient mice. Blood 104, 65-72. doi: 10.1182/blood-2003-05-1589

Levoye, A., Balabanian, K., Baleux, F., Bachelerie, F., and Lagane, B. (2009). CXCR7 heterodimerizes with CXCR4 and regulates CXCL12-mediated G protein signaling. Blood 113, 6085-6093. doi: 10.1182/blood-2008-12-196618

Li, D., Yan, D., Liu, W., Li, M., Yu, J., Li, Y., et al. (2011). Foxc2 overexpression enhances benefit of endothelial progenitor cells for inhibiting neointimal formation by promoting CXCR4-dependent homing. J. Vasc. Surg. 53, 1668-1678. doi: 10.1016/j.jvs.2011.01.044

Li, F., Guo, W. Y., Li, W. J., Zhang, D. X., Lv, A. L., Luan, R. H., et al. (2009). Cyclic stretch upregulates SDF-1alpha/CXCR4 axis in human saphenous vein smooth muscle cells. Biochem. Biophys. Res. Commun. 386, 247-251. doi: 10.1016/j.bbrc.2009.06.025

Li, L. X., Zhang, X. F., Bai, X., and Tong, Q. (2013). SDF-1 promotes ox-LDL induced vascular smooth muscle cell proliferation. Cell Biol. Int. 37, 988-994. doi: 10.1002/cbin.10126

Li, M., Yu, J., Li, Y., Li, D., Yan, D., Qu, Z., et al. (2010). CXCR4 positive bone mesenchymal stem cells migrate to human endothelial cell stimulated by oxLDL via SDF-1alpha/CXCR4 signaling axis. Exp. Mol. Pathol. 88, 250-255. doi: 10.1016/j.yexmp.2009.12.001

Li, X., Zhu, M., Penfold, M. E., Koenen, R. R., Thiemann, A., Heyll, K., et al. (2014). Activation of CXCR7 limits atherosclerosis and improves hyperlipidemia by increasing cholesterol uptake in adipose tissue. Circulation 129, 1244-1253. doi: 10.1161/CIRCULATIONAHA.113.006840

Liehn, E. A., Kanzler, I., Konschalla, S., Kroh, A., Simsekyilmaz, S., Sonmez, T. T., et al. (2013a). Compartmentalized protective and detrimental effects of endogenous macrophage migration-inhibitory factor mediated by CXCR2 in a mouse model of myocardial ischemia/reperfusion. Arterioscler. Thromb. Vasc. Biol. 33, 2180-2186. doi: 10.1161/ATVBAHA.113.301633

Liehn, E. A., Radu, E., and Schuh, A. (2013b). Chemokine contribution in stem cell engraftment into the infarcted myocardium. Curr. Stem Cell Res. Ther. 8, 278-283. doi: 10.2174/1574888X11308040003

Liehn, E. A., Tuchscheerer, N., Kanzler, I., Drechsler, M., Fraemohs, L., Schuh, A., et al. (2011). Double-edged role of the CXCL12/CXCR4 axis in experimental myocardial infarction. J. Am. Coll. Cardiol. 58, 2415-2423. doi: 10.1016/j.jacc.2011.08.033

Lievens, D., and Von Hundelshausen, P. (2011). Platelets in atherosclerosis. Thromb. Haemost. 106, 827-838. doi: 10.1160/TH11-08-0592

Liu, Z., Han, Y., Li, L., Lu, H., Meng, G., Li, X., et al. (2013). The hydrogen sulfide donor, GYY4137, exhibits anti-atherosclerotic activity in high fat fed apolipoprotein E(-/-) mice. Br. J. Pharmacol. 169, 1795-1809. doi: 10.1111/bph.12246

Luker, K. E., Steele, J. M., Mihalko, L. A., Ray, P., and Luker, G. D. (2010). Constitutive and chemokine-dependent internalization and recycling of CXCR7 in breast cancer cells to degrade chemokine ligands. Oncogene 29, 4599-4610. doi: 10.1038/onc.2010.212

Ma, Q., Jones, D., Borghesani, P. R., Segal, R. A., Nagasawa, T., Kishimoto, T., et al. (1998). Impaired B-lymphopoiesis, myelopoiesis, and derailed cerebellar neuron migration in CXCR4- and SDF-1-deficient mice. Proc. Natl. Acad. Sci. U.S.A. 95, 9448-9453. doi: 10.1073/pnas.95.16.9448

Ma, W., Liu, Y., Ellison, N., and Shen, J. (2013). Induction of C-X-C chemokine receptor type 7 (CXCR7) switches stromal cell-derived factor-1 (SDF-1) signaling and phagocytic activity in macrophages linked to atherosclerosis. J. Biol. Chem. 288, 15481-15494. doi: 10.1074/jbc.M112.445510

Makino, A., Nakamura, T., Hirano, M., Kitta, Y., Sano, K., Kobayashi, T., et al. (2010). High plasma levels of macrophage migration inhibitory factor are associated with adverse long-term outcome in patients with stable coronary artery disease and impaired glucose tolerance or type 2 diabetes mellitus. Atherosclerosis 213, 573-578. doi: 10.1016/j.atherosclerosis.2010.09.004

Maouche, S., and Schunkert, H. (2012). Strategies beyond genome-wide association studies for atherosclerosis. Arterioscler. Thromb. Vasc. Biol. 32, 170-181. doi: 10.1161/ATVBAHA.111.232652

Marsch, E., Sluimer, J. C., and Daemen, M. J. (2013). Hypoxia in atherosclerosis and inflammation. Curr. Opin. Lipidol. 24, 393-400. doi: 10.1097/MOL.0b013e32 $836484 \mathrm{a} 4$

Martin, C., Burdon, P. C., Bridger, G., Gutierrez-Ramos, J. C., Williams, T. J., and Rankin, S. M. (2003). Chemokines acting via CXCR2 and CXCR4 control the release of neutrophils from the bone marrow and their return following senescence. Immunity 19, 583-593. doi: 10.1016/S1074-7613(03)00263-2

Mazo, I. B., Massberg, S., and Von Andrian, U. H. (2011). Hematopoietic stem and progenitor cell trafficking. Trends Immunol. 32, 493-503. doi: 10.1016/j.it.2011.06.011

Mehta, N. N., Li, M., William, D., Khera, A. V., Derohannessian, S., Qu, L., et al. (2011). The novel atherosclerosis locus at $10 \mathrm{q} 11$ regulates plasma CXCL12 levels. Eur. Heart J. 32, 963-971. doi: 10.1093/eurheartj/ehr091

Melchionna, R., Porcelli, D., Mangoni, A., Carlini, D., Liuzzo, G., Spinetti, G., et al. (2005). Laminar shear stress inhibits CXCR4 expression on endothelial cells: functional consequences for atherogenesis. FASEB J. 19, 629-631. doi: 10.1096/ fj.04-2219fje

Melchionna, R., Romani, M., Ambrosino, V., D’arcangelo, D., Cencioni, C., Porcelli, D., et al. (2010). Role of HIF-1alpha in proton-mediated CXCR4 down-regulation in endothelial cells. Cardiovasc. Res. 86, 293-301. doi: $10.1093 / \mathrm{cvr} / \mathrm{cvp} 393$

Mendez-Ferrer, S., Battista, M., and Frenette, P. S. (2010). Cooperation of beta(2)and beta(3)-adrenergic receptors in hematopoietic progenitor cell mobilization. Ann. N.Y. Acad. Sci. 1192, 139-144. doi: 10.1111/j.1749-6632.2010.05390.x

Merkulova-Rainon, T., Broqueres-You, D., Kubis, N., Silvestre, J. S., and Levy, B. I. (2012). Towards the therapeutic use of vascular smooth muscle progenitor cells. Cardiovasc. Res. 95, 205-214. doi: 10.1093/cvr/cvs097

Miller, E. J., Li, J., Leng, L., Mcdonald, C., Atsumi, T., Bucala, R., et al. (2008) Macrophage migration inhibitory factor stimulates AMP-activated protein kinase in the ischaemic heart. Nature 451, 578-582. doi: 10.1038/nature06504

Molino, M., Woolkalis, M. J., Prevost, N., Pratico, D., Barnathan, E. S., Taraboletti, G., et al. (2000). CXCR4 on human endothelial cells can serve as both a mediator of biological responses and as a receptor for HIV-2. Biochim. Biophys. Acta 1500, 227-240. doi: 10.1016/S0925-4439(99)00110-6 
Moore, M. A., Hattori, K., Heissig, B., Shieh, J. H., Dias, S., Crystal, R. G., et al. (2001). Mobilization of endothelial and hematopoietic stem and progenitor cells by adenovector-mediated elevation of serum levels of SDF-1, VEGF, and angiopoietin-1. Ann. N.Y. Acad. Sci. 938, 36-45; discussion: 45-37. doi: 10.1111/ j.1749-6632.2001.tb03572.x

Muller, I. I., Muller, K. A., Schonleber, H., Karathanos, A., Schneider, M., Jorbenadze, R., et al. (2012). Macrophage migration inhibitory factor is enhanced in acute coronary syndromes and is associated with the inflammatory response. PLoS ONE 7:e38376. doi: 10.1371/journal.pone.0038376

Murphy, P. M., Baggiolini, M., Charo, I. F., Hebert, C. A., Horuk, R., Matsushima, K., et al. (2000). International union of pharmacology. XXII. Nomenclature for chemokine receptors. Pharmacol. Rev. 52, 145-176.

Nagasawa, T., Hirota, S., Tachibana, K., Takakura, N., Nishikawa, S., Kitamura, Y., et al. (1996). Defects of B-cell lymphopoiesis and bone-marrow myelopoiesis in mice lacking the CXC chemokine PBSF/SDF-1. Nature 382, 635-638. doi: $10.1038 / 382635 \mathrm{a} 0$

Naumann, U., Cameroni, E., Pruenster, M., Mahabaleshwar, H., Raz, E., Zerwes, H. G., et al. (2010). CXCR7 functions as a scavenger for CXCL12 and CXCL11. PLoS ONE 5:e9175. doi: 10.1371/journal.pone.0009175

Nemenoff, R. A., Horita, H., Ostriker, A. C., Furgeson, S. B., Simpson, P. A., Vanputten, V., et al. (2011). SDF-1alpha induction in mature smooth muscle cells by inactivation of PTEN is a critical mediator of exacerbated injuryinduced neointima formation. Arterioscler. Thromb. Vasc. Biol. 31, 1300-1308. doi: 10.1161/ATVBAHA.111.223701

Nemenoff, R. A., Simpson, P. A., Furgeson, S. B., Kaplan-Albuquerque, N., Crossno, J., Garl, P. J., et al. (2008). Targeted deletion of PTEN in smooth muscle cells results in vascular remodeling and recruitment of progenitor cells through induction of stromal cell-derived factor-1alpha. Circ. Res. 102, 1036-1045. doi: 10.1161/CIRCRESAHA.107.169896

Nie, Y., Waite, J., Brewer, F., Sunshine, M. J., Littman, D. R., and Zou, Y. R. (2004). The role of CXCR4 in maintaining peripheral B cell compartments and humoral immunity. J. Exp. Med. 200, 1145-1156. doi: 10.1084/jem.20041185

Noels, H., Zhou, B., Tilstam, P. V., Theelen, W., Li, X., Pawig, L., et al. (2014). Deficiency of endothelial Cxcr4 reduces reendothelialization and enhances neointimal hyperplasia after vascular injury in atherosclerosis-prone mice. Arterioscler. Thromb. Vasc. Biol. 34, 1209-1220. doi: 10.1161/ATVBAHA.113. 302878

Oberlin, E., Amara, A., Bachelerie, F., Bessia, C., Virelizier, J. L., ArenzanaSeisdedos, F., et al. (1996). The CXC chemokine SDF-1 is the ligand for LESTR/fusin and prevents infection by T-cell-line-adapted HIV-1. Nature 382, 833-835. doi: 10.1038/382833a0

O'boyle, G., Mellor, P., Kirby, J. A., and Ali, S. (2009). Anti-inflammatory therapy by intravenous delivery of non-heparan sulfate-binding CXCL12. FASEB J. 23, 3906-3916. doi: 10.1096/fj.09-134643

Ocana, E., Perez-Requena, J., Bohorquez, J. C., Brieva, J. A., and Rodriguez, C. (2008). Chemokine receptor expression on infiltrating lymphocytes from abdominal aortic aneurysms: role of CXCR4-CXCL12 in lymphoid recruitment. Atherosclerosis 200, 264-270. doi: 10.1016/j.atherosclerosis.2007.12.043

Okabe, S., Fukuda, S., Kim, Y. J., Niki, M., Pelus, L. M., Ohyashiki, K., et al. (2005). Stromal cell-derived factor-1alpha/CXCL12-induced chemotaxis of T cells involves activation of the RasGAP-associated docking protein p62Dok-1. Blood 105, 474-480. doi: 10.1182/blood-2004-03-0843

Olive, M., Mellad, J. A., Beltran, L. E., Ma, M., Cimato, T., Noguchi, A. C., et al. (2008). p21Cip1 modulates arterial wound repair through the stromal cell-derived factor-1/CXCR4 axis in mice. J. Clin. Invest. 118, 2050-2061. doi: 10.1172/JCI31244

Orsini, M. J., Parent, J.-L., Mundell, S. J., and Benovic, J. L. (1999). Trafficking of the HIV Coreceptor CXCR4: role of arrestins and identification of residues in the c-terminal tail that mediate receptor internalization. J. Biol. Chem. 274, 31076-31086. doi: 10.1074/jbc.274.43.31076

Owens, G. K., Kumar, M. S., and Wamhoff, B. R. (2004). Molecular regulation of vascular smooth muscle cell differentiation in development and disease. Physiol. Rev. 84, 767-801. doi: 10.1152/physrev.00041.2003

Pan, C. H., Chen, C. W., Sheu, M. J., and Wu, C. H. (2012). Salvianolic acid $\mathrm{B}$ inhibits SDF-1alpha-stimulated cell proliferation and migration of vascular smooth muscle cells by suppressing CXCR4 receptor. Vascul. Pharmacol. 56, 98-105. doi: 10.1016/j.vph.2011.11.008

Pan, J. H., Sukhova, G. K., Yang, J. T., Wang, B., Xie, T., Fu, H., et al. (2004). Macrophage migration inhibitory factor deficiency impairs atherosclerosis in low-density lipoprotein receptor-deficient mice. Circulation 109, 3149-3153. doi: 10.1161/01.CIR.0000134704.84454.D2

Peden, J. F., Hopewell, J. C., Saleheen, D., Chambers, J. C., Hager, J., Soranzo, N., et al. (2011). C4D Genetics Consortium. A genome-wide association study in Europeans and South Asians identifies five new loci for coronary artery disease. Nat. Genet. 43, 339-344. doi: 10.1038/ng.782

Peled, A., Kollet, O., Ponomaryov, T., Petit, I., Franitza, S., Grabovsky, V., et al. (2000). The chemokine SDF-1 activates the integrins LFA-1, VLA-4, and VLA-5 on immature human CD34(+) cells: role in transendothelial/stromal migration and engraftment of NOD/SCID mice. Blood 95, 3289-3296.

Petit, I., Szyper-Kravitz, M., Nagler, A., Lahav, M., Peled, A., Habler, L., et al. (2002). G-CSF induces stem cell mobilization by decreasing bone marrow SDF-1 and up-regulating CXCR4. Nat. Immunol. 3, 687-694. doi: 10.1038/ni813

Pillarisetti, K., and Gupta, S. K. (2001). Cloning and relative expression analysis of rat stromal cell derived factor-1 (SDF-1)1: SDF-1 alpha mRNA is selectively induced in rat model of myocardial infarction. Inflammation 25, 293-300. doi: 10.1023/A:1012808525370

Poznansky, M. C., Olszak, I. T., Foxall, R., Evans, R. H., Luster, A. D., and Scadden, D. T. (2000). Active movement of T cells away from a chemokine. Nat. Med. 6, 543-548. doi: 10.1038/75022

Proulx, C., El-Helou, V., Gosselin, H., Clement, R., Gillis, M. A., Villeneuve, L., et al. (2007). Antagonism of stromal cell-derived factor-lalpha reduces infarct size and improves ventricular function after myocardial infarction. Pflugers Arch. 455, 241-250. doi: 10.1007/s00424-007-0284-5

Purcell, B. P., Elser, J. A., Mu, A., Margulies, K. B., and Burdick, J. A. (2012). Synergistic effects of SDF-1alpha chemokine and hyaluronic acid release from degradable hydrogels on directing bone marrow derived cell homing to the myocardium. Biomaterials 33, 7849-7857. doi: 10.1016/j.biomaterials.2012. 07.005

Qi, D., Hu, X., Wu, X., Merk, M., Leng, L., Bucala, R., et al. (2009). Cardiac macrophage migration inhibitory factor inhibits JNK pathway activation and injury during ischemia/reperfusion. J. Clin. Invest. 119, 3807-3816. doi: 10.1172/JCI39738

Rajagopal, S., Kim, J., Ahn, S., Craig, S., Lam, C. M., Gerard, N. P., et al. (2010). Beta-arrestin- but not $G$ protein-mediated signaling by the "decoy" receptor CXCR7. Proc. Natl. Acad. Sci. U.S.A. 107, 628-632. doi: $10.1073 /$ pnas.0912852107

Rajagopalan, L., and Rajarathnam, K. (2006). Structural basis of chemokine receptor function-a model for binding affinity and ligand selectivity. Biosci. Rep. 26, 325-339. doi: 10.1007/s10540-006-9025-9

Rath, D., Chatterjee, M., Borst, O., Muller, K., Stellos, K., Mack, A. F., et al. (2014). Expression of stromal cell-derived factor-1 receptors CXCR4 and CXCR7 on circulating platelets of patients with acute coronary syndrome and association with left ventricular functional recovery. Eur. Heart J. 35, 386-394. doi: 10.1093/eurheartj/eht448

Ray, P., Lewin, S. A., Mihalko, L. A., Lesher-Perez, S. C., Takayama, S., Luker, K. E., et al. (2012). Secreted CXCL12 (SDF-1) forms dimers under physiological conditions. Biochem. J. 442, 433-442. doi: 10.1042/BJ20111341

Rennert, R. C., Sorkin, M., Garg, R. K., and Gurtner, G. C. (2012). Stem cell recruitment after injury: lessons for regenerative medicine. Regen. Med. 7, 833-850. doi: $10.2217 /$ rme.12.82

Rettig, M. P., Ansstas, G., and Dipersio, J. F. (2012). Mobilization of hematopoietic stem and progenitor cells using inhibitors of CXCR4 and VLA-4. Leukemia 26, 34-53. doi: 10.1038/leu.2011.197

Ripatti, S., Tikkanen, E., Orho-Melander, M., Havulinna, A. S., Silander, K., Sharma, A., et al. (2010). A multilocus genetic risk score for coronary heart disease: case-control and prospective cohort analyses. Lancet 376, 1393-1400. doi: 10.1016/S0140-6736(10)61267-6

Salcedo, R., Wasserman, K., Young, H. A., Grimm, M. C., Howard, O. M., Anver, M. R., et al. (1999). Vascular endothelial growth factor and basic fibroblast growth factor induce expression of CXCR4 on human endothelial cells: in vivo neovascularization induced by stromal-derived factor-1alpha. Am. J. Pathol. 154, 1125-1135. doi: 10.1016/S0002-9440(10)65365-5

Salcedo, R., Zhang, X., Young, H. A., Michael, N., Wasserman, K., Ma, W. H., et al. (2003). Angiogenic effects of prostaglandin E2 are mediated by up-regulation of CXCR4 on human microvascular endothelial cells. Blood 102, 1966-1977. doi: 10.1182/blood-2002-11-3400

Salvucci, O., Basik, M., Yao, L., Bianchi, R., and Tosato, G. (2004). Evidence for the involvement of SDF-1 and CXCR4 in the disruption of endothelial 
cell-branching morphogenesis and angiogenesis by TNF-alpha and IFNgamma. J. Leukoc. Biol. 76, 217-226. doi: 10.1189/jlb.1203609

Samani, N. J., Erdmann, J., Hall, A. S., Hengstenberg, C., Mangino, M., Mayer, B., et al. (2007). Genomewide association analysis of coronary artery disease. $N$. Engl. J. Med. 357, 443-453. doi: 10.1056/NEJMoa072366

Sanchez-Alcaniz, J. A., Haege, S., Mueller, W., Pla, R., Mackay, F., Schulz, S., et al. (2011). Cxcr7 controls neuronal migration by regulating chemokine responsiveness. Neuron 69, 77-90. doi: 10.1016/j.neuron.2010.12.006

Sanchez-Martin, L., Estecha, A., Samaniego, R., Sanchez-Ramon, S., Vega, M. A., and Sanchez-Mateos, P. (2011). The chemokine CXCL12 regulates monocytemacrophage differentiation and RUNX3 expression. Blood 117, 88-97. doi: 10.1182/blood-2009-12-258186

Sanganalmath, S. K., and Bolli, R. (2013). Cell therapy for heart failure: a comprehensive overview of experimental and clinical studies, current challenges, and future directions. Circ. Res. 113, 810-834. doi: 10.1161/CIRCRESAHA.113.300219

Sata, M., Saiura, A., Kunisato, A., Tojo, A., Okada, S., Tokuhisa, T., et al. (2002). Hematopoietic stem cells differentiate into vascular cells that participate in the pathogenesis of atherosclerosis. Nat. Med. 8, 403-409. doi: 10.1038/nm0402-403

Saxena, A., Fish, J. E., White, M. D., Yu, S., Smyth, J. W., Shaw, R. M., et al. (2008). Stromal cell-derived factor-lalpha is cardioprotective after myocardial infarction. Circulation 117, 2224-2231. doi: 10.1161/CIRCULATIONAHA.107.694992

Schecter, A. D., Berman, A. B., Yi, L., Mosoian, A., Mcmanus, C. M., Berman, J. W., et al. (2001). HIV envelope gp120 activates human arterial smooth muscle cells. Proc. Natl. Acad. Sci. U.S.A. 98, 10142-10147. doi: 10.1073/pnas.181328798

Schioppa, T., Uranchimeg, B., Saccani, A., Biswas, S. K., Doni, A., Rapisarda, A., et al. (2003). Regulation of the chemokine receptor CXCR4 by hypoxia. J. Exp. Med. 198, 1391-1402. doi: 10.1084/jem.20030267

Schiraldi, M., Raucci, A., Munoz, L. M., Livoti, E., Celona, B., Venereau, E., et al. (2012). HMGB1 promotes recruitment of inflammatory cells to damaged tissues by forming a complex with CXCL12 and signaling via CXCR4. J. Exp. Med. 209, 551-563. doi: 10.1084/jem.20111739

Schober, A., Karshovska, E., Zernecke, A., and Weber, C. (2006). SDF-1alphamediated tissue repair by stem cells: a promising tool in cardiovascular medicine? Trends Cardiovasc. Med. 16, 103-108. doi: 10.1016/j.tcm.2006.01.006

Schober, A., Knarren, S., Lietz, M., Lin, E. A., and Weber, C. (2003). Crucial role of stromal cell-derived factor-1alpha in neointima formation after vascular injury in apolipoprotein E-deficient mice. Circulation 108, 2491-2497. doi: 10.1161/01.CIR.0000099508.76665.9A

Schuh, A., Kroh, A., Konschalla, S., Liehn, E. A., Sobota, R. M., Biessen, E. A., et al. (2012). Myocardial regeneration by transplantation of modified endothelial progenitor cells expressing SDF-1 in a rat model. J. Cell. Mol. Med. 16, 2311-2320. doi: 10.1111/j.1582-4934.2012.01539.x

Schuh, A., Liehn, E. A., Sasse, A., Hristov, M., Sobota, R., Kelm, M., et al. (2008). Transplantation of endothelial progenitor cells improves neovascularization and left ventricular function after myocardial infarction in a rat model. Basic Res. Cardiol. 103, 69-77. doi: 10.1007/s00395-007-0685-9

Schunkert, H., Konig, I. R., Kathiresan, S., Reilly, M. P., Assimes, T. L., Holm, H., et al. (2011). Large-scale association analysis identifies 13 new susceptibility loci for coronary artery disease. Nat. Genet. 43, 333-338. doi: 10.1038/ng.784

Schutyser, E., Su, Y., Yu, Y., Gouwy, M., Zaja-Milatovic, S., Van Damme, J., et al. (2007). Hypoxia enhances CXCR4 expression in human microvascular endothelial cells and human melanoma cells. Eur. Cytokine Netw. 18, 59-70. doi: 10.1684/ecn.2007.0087

Segers, V. F., Tokunou, T., Higgins, L. J., Macgillivray, C., Gannon, J., and Lee, R. T. (2007). Local delivery of protease-resistant stromal cell derived factor-1 for stem cell recruitment after myocardial infarction. Circulation 116, 1683-1692. doi: 10.1161/CIRCULATIONAHA.107.718718

Semerad, C. L., Christopher, M. J., Liu, F., Short, B., Simmons, P. J., Winkler, I., et al. (2005). G-CSF potently inhibits osteoblast activity and CXCL12 mRNA expression in the bone marrow. Blood 106, 3020-3027. doi: 10.1182/blood2004-01-0272

Shiba, Y., Takahashi, M., Yoshioka, T., Yajima, N., Morimoto, H., Izawa, A., et al. (2007). M-CSF accelerates neointimal formation in the early phase after vascular injury in mice: the critical role of the SDF-1-CXCR4 system. Arterioscler. Thromb. Vasc. Biol. 27, 283-289. doi: 10.1161/01.ATV.0000250606.70669.14

Shirozu, M., Nakano, T., Inazawa, J., Tashiro, K., Tada, H., Shinohara, T., et al. (1995). Structure and chromosomal localization of the human
Stromal Cell-Derived Factor 1 (SDF1) gene. Genomics 28, 495-500. doi: 10.1006/geno.1995.1180

Sierro, F., Biben, C., Martinez-Munoz, L., Mellado, M., Ransohoff, R. M., Li, M., et al. (2007). Disrupted cardiac development but normal hematopoiesis in mice deficient in the second CXCL12/SDF-1 receptor, CXCR7. Proc. Natl. Acad. Sci. U.S.A. 104, 14759-14764. doi: 10.1073/pnas.0702229104

Simons, D., Grieb, G., Hristov, M., Pallua, N., Weber, C., Bernhagen, J., et al. (2011). Hypoxia-induced endothelial secretion of macrophage migration inhibitory factor and role in endothelial progenitor cell recruitment. J. Cell. Mol. Med. 15, 668-678. doi: 10.1111/j.1582-4934.2010.01041.x

Steinmetz, M., Nickenig, G., and Werner, N. (2010). Endothelial-regenerating cells: an expanding universe. Hypertension 55, 593-599. doi: 10.1161/ HYPERTENSIONAHA.109.134213

Stellos, K., Bigalke, B., Langer, H., Geisler, T., Schad, A., Kogel, A., et al. (2009). Expression of stromal-cell-derived factor-1 on circulating platelets is increased in patients with acute coronary syndrome and correlates with the number of CD34+ progenitor cells. Eur. Heart J. 30, 584-593. doi: 10.1093/eurheartj/ehn566

Tachibana, K., Hirota, S., Iizasa, H., Yoshida, H., Kawabata, K., Kataoka, Y., et al. (1998). The chemokine receptor CXCR4 is essential for vascularization of the gastrointestinal tract. Nature 393, 591-594. doi: 10.1038/31261

Takagi, Y., Hashimoto, N., Phan, S. H., Imaizumi, K., Matsuo, M., Nakashima, H., et al. (2009). Erythromycin-induced CXCR4 expression on microvascular endothelial cells. Am. J. Physiol. Lung Cell. Mol. Physiol. 297, L420-L431. doi: 10.1152/ajplung.90477.2008

Tanaka, G., Nakase, I., Fukuda, Y., Masuda, R., Oishi, S., Shimura, K., et al. (2012). CXCR4 stimulates macropinocytosis: implications for cellular uptake of arginine-rich cell-penetrating peptides and HIV. Chem. Biol. 19, 1437-1446. doi: 10.1016/j.chembiol.2012.09.011

Tanaka, K., and Sata, M. (2008). Contribution of circulating vascular progenitors in lesion formation and vascular healing: lessons from animal models. Curr. Opin. Lipidol. 19, 498-504. doi: 10.1097/MOL.0b013e32830dd566

Tang, J. M., Wang, J. N., Zhang, L., Zheng, F., Yang, J. Y., Kong, X., et al. (2011). VEGF/SDF-1 promotes cardiac stem cell mobilization and myocardial repair in the infarcted heart. Cardiovasc. Res. 91, 402-411. doi: 10.1093/cvr/cvr053

Teicher, B. A., and Fricker, S. P. (2010). CXCL12 (SDF-1)/CXCR4 pathway in cancer. Clin. Cancer Res. 16, 2927-2931. doi: 10.1158/1078-0432.CCR-09-2329

Tillmann, S., Bernhagen, J., and Noels, H. (2013). Arrest functions of the MIF ligand/receptor axes in atherogenesis. Front. Immunol. 4:115. doi: 10.3389/fimmu.2013.00115

Unoki, N., Murakami, T., Nishijima, K., Ogino, K., Van Rooijen, N., and Yoshimura, N. (2010). SDF-1/CXCR4 contributes to the activation of tip cells and microglia in retinal angiogenesis. Invest. Ophthalmol. Vis. Sci. 51, 3362-3371. doi: 10.1167/iovs.09-4978

Uto-Konomi, A., Mckibben, B., Wirtz, J., Sato, Y., Takano, A., Nanki, T., et al. (2013). CXCR7 agonists inhibit the function of CXCL12 by downregulation of CXCR4. Biochem. Biophys. Res. Commun. 431, 772-776. doi: 10.1016/j.bbrc.2013.01.032

Vasa, M., Fichtlscherer, S., Aicher, A., Adler, K., Urbich, C., Martin, H., et al. (2001). Number and migratory activity of circulating endothelial progenitor cells inversely correlate with risk factors for coronary artery disease. Circ. Res. 89, E1-E7. doi: 10.1161/hh1301.093953

Volin, M. V., Joseph, L., Shockley, M. S., and Davies, P. F. (1998). Chemokine receptor CXCR4 expression in endothelium. Biochem. Biophys. Res. Commun. 242, 46-53. doi: 10.1006/bbrc. 1997.7890

Wagner, N. M., Bierhansl, L., Noldge-Schomburg, G., Vollmar, B., and Roesner, J. P. (2013). Toll-like receptor 2-blocking antibodies promote angiogenesis and induce ERK1/2 and AKT signaling via CXCR4 in endothelial cells. Arterioscler. Thromb. Vasc. Biol. 33, 1943-1951. doi: 10.1161/ATVBAHA.113.301783

Wang, J. F., Liu, Z. Y., and Groopman, J. E. (1998). The alpha-chemokine receptor CXCR4 is expressed on the megakaryocytic lineage from progenitor to platelets and modulates migration and adhesion. Blood 92, 756-764.

Wang, Y., Li, G., Stanco, A., Long, J. E., Crawford, D., Potter, G. B., et al. (2011). CXCR4 and CXCR7 have distinct functions in regulating interneuron migration. Neuron 69, 61-76. doi: 10.1016/j.neuron.2010.12.005

Weber, C., and Noels, H. (2011). Atherosclerosis: current pathogenesis and therapeutic options. Nat. Med. 17, 1410-1422. doi: 10.1038/nm.2538

Werner, N., Junk, S., Laufs, U., Link, A., Walenta, K., Bohm, M., et al. (2003). Intravenous transfusion of endothelial progenitor cells reduces 
neointima formation after vascular injury. Circ. Res. 93, e17-e24. doi: 10.1161/01.RES.0000083812.30141.74

White, D. A., Fang, L., Chan, W., Morand, E. F., Kiriazis, H., Duffy, S. J., et al. (2013). Pro-inflammatory action of MIF in acute myocardial infarction via activation of peripheral blood mononuclear cells. PLOS ONE 8:e76206. doi: 10.1371/annotation/6e24b7bb-83c7-4887-9621-96b64acfb1c1

Winkler, I. G., Sims, N. A., Pettit, A. R., Barbier, V., Nowlan, B., Helwani, F., et al. (2010). Bone marrow macrophages maintain hematopoietic stem cell (HSC) niches and their depletion mobilizes HSCs. Blood 116, 4815-4828. doi: 10.1182/blood-2009-11-253534

Yamani, M. H., Ratliff, N. B., Cook, D. J., Tuzcu, E. M., Yu, Y., Hobbs, R., et al. (2005). Peritransplant ischemic injury is associated with up-regulation of stromal cell-derived factor-1. J. Am. Coll. Cardiol. 46, 1029-1035. doi: 10.1016/j.jacc.2005.04.059

Yao, L., Heuser-Baker, J., Herlea-Pana, O., Iida, R., Wang, Q., Zou, M. H., et al. (2012). Bone marrow endothelial progenitors augment atherosclerotic plaque regression in a mouse model of plasma lipid lowering. Stem Cells 30, 2720-2731. doi: 10.1002/stem.1256

Yin, Y., Zhao, X., Fang, Y., Yu, S., Zhao, J., Song, M., et al. (2010). SDF1alpha involved in mobilization and recruitment of endothelial progenitor cells after arterial injury in mice. Cardiovasc. Pathol. 19, 218-227. doi: 10.1016/j.carpath.2009.04.002

Ylitalo, R., Oksala, O., Yla-Herttuala, S., and Ylitalo, P. (1994). Effects of clodronate (dichloromethylene bisphosphonate) on the development of experimental atherosclerosis in rabbits. J. Lab. Clin. Med. 123, 769-776.

Yoshioka, T., Takahashi, M., Shiba, Y., Suzuki, C., Morimoto, H., Izawa, A., et al. (2006). Granulocyte colony-stimulating factor (G-CSF) accelerates reendothelialization and reduces neointimal formation after vascular injury in mice. Cardiovasc. Res. 70, 61-69. doi: 10.1016/j.cardiores.2005.12.013

Yu, C. M., Lai, K. W., Chen, Y. X., Huang, X. R., and Lan, H. Y. (2003). Expression of macrophage migration inhibitory factor in acute ischemic myocardial injury. J. Histochem. Cytochem. 51, 625-631. doi: 10.1177/00221554030 5100508

Yu, C. M., Lau, C. P., Lai, K. W., Huang, X. R., Chen, W. H., and Lan, H. Y. (2001). Elevation of plasma level of macrophage migration inhibitory factor in patients with acute myocardial infarction. Am. J. Cardiol. 88, 774-777. doi: 10.1016/S0002-9149(01)01850-1

Yu, H., Stoneman, V., Clarke, M., Figg, N., Xin, H. B., Kotlikoff, M., et al. (2011a). Bone marrow-derived smooth muscle-like cells are infrequent in advanced primary atherosclerotic plaques but promote atherosclerosis. Arterioscler. Thromb. Vasc. Biol. 31, 1291-1299. doi: 10.1161/ATVBAHA.110.218578

Yu, J., Li, M., Qu, Z., Yan, D., Li, D., and Ruan, Q. (2010). SDF-1/CXCR4-mediated migration of transplanted bone marrow stromal cells toward areas of heart myocardial infarction through activation of PI3K/Akt. J. Cardiovasc. Pharmacol. 55, 496-505. doi: 10.1097/FJC.0b013e3181d7a384

Yu, L., Cecil, J., Peng, S.-B., Schrementi, J., Kovacevic, S., Paul, D., et al. (2006). Identification and expression of novel isoforms of human stromal cell-derived factor 1. Gene 374, 174-179. doi: 10.1016/j.gene.2006.02.001

Yu, S., Crawford, D., Tsuchihashi, T., Behrens, T. W., and Srivastava, D. (2011b). The chemokine receptor CXCR7 functions to regulate cardiac valve remodeling. Dev. Dyn. 240, 384-393. doi: 10.1002/dvdy.22549

Zernecke, A., Bidzhekov, K., Noels, H., Shagdarsuren, E., Gan, L., Denecke, B., et al. (2009). Delivery of MicroRNA-126 by apoptotic bodies induces
CXCL12-dependent vascular protection. Sci. Signal. 2:ra81. doi: 10.1126/scisignal.2000610

Zernecke, A., Bot, I., Djalali-Talab, Y., Shagdarsuren, E., Bidzhekov, K., Meiler, S., et al. (2008). Protective role of CXC receptor 4/CXC ligand 12 unveils the importance of neutrophils in atherosclerosis. Circ. Res. 102, 209-217. doi: 10.1161/CIRCRESAHA.107.160697

Zernecke, A., Schober, A., Bot, I., Von Hundelshausen, P., Liehn, E. A., Mopps, B., et al. (2005). SDF-1alpha/CXCR4 axis is instrumental in neointimal hyperplasia and recruitment of smooth muscle progenitor cells. Circ. Res. 96, 784-791. doi: 10.1161/01.RES.0000162100.52009.38

Zernecke, A., and Weber, C. (2014). Chemokines in atherosclerosis: proceedings resumed. Arterioscler. Thromb. Vasc. Biol. 34, 742-750. doi: 10.1161/ATVBAHA. 113.301655

Zhang, D., Fan, G. C., Zhou, X., Zhao, T., Pasha, Z., Xu, M., et al. (2008). Overexpression of CXCR4 on mesenchymal stem cells augments myoangiogenesis in the infarcted myocardium. J. Mol. Cell. Cardiol. 44, 281-292. doi: 10.1016/j. yjmcc.2007.11.010

Zhang, L., Brian, L., and Freedman, N. J. (2012). Vein graft neointimal hyperplasia is exacerbated by CXCR4 signaling in vein graft-extrinsic cells. J. Vasc. Surg. 56, 1390-1397. doi: 10.1016/j.jvs.2012.03.254

Zhang, M., Mal, N., Kiedrowski, M., Chacko, M., Askari, A. T., Popovic, Z. B., et al. (2007). SDF-1 expression by mesenchymal stem cells results in trophic support of cardiac myocytes after myocardial infarction. FASEB J. 21, 3197-3207. doi: 10.1096/fj.06-6558com

Zhang, X., Nakajima, T., Goronzy, J. J., and Weyand, C. M. (2005). Tissue trafficking patterns of effector memory CD4+ T cells in rheumatoid arthritis. Arthritis Rheum. 52, 3839-3849. doi: 10.1002/art.21482

Zoll, J., Fontaine, V., Gourdy, P., Barateau, V., Vilar, J., Leroyer, A., et al. (2008). Role of human smooth muscle cell progenitors in atherosclerotic plaque development and composition. Cardiovasc. Res. 77, 471-480. doi: 10.1093/cvr/ cvm034

Zou, Y. R., Kottmann, A. H., Kuroda, M., Taniuchi, I., and Littman, D. R. (1998). Function of the chemokine receptor CXCR4 in haematopoiesis and in cerebellar development. Nature 393, 595-599. doi: 10.1038/31269

Conflict of Interest Statement: Christian Weber is consultant of Carolus Therapeutics Inc., a US-based biotech company developing chemokine-based anti-inflammatory strategies. The authors declare that the research was conducted in the absence of any commercial or financial relationships that could be construed as a potential conflict of interest.

Received: 28 February 2014; accepted: 15 May 2014; published online: 11 June 2014. Citation: Döring Y, Pawig L, Weber C and Noels H (2014) The CXCL12/CXCR4 chemokine ligand/receptor axis in cardiovascular disease. Front. Physiol. 5:212. doi: $10.3389 /$ fphys.2014.00212

This article was submitted to Vascular Physiology, a section of the journal Frontiers in Physiology.

Copyright (c) 2014 Döring, Pawig, Weber and Noels. This is an open-access article distributed under the terms of the Creative Commons Attribution License (CC BY). The use, distribution or reproduction in other forums is permitted, provided the original author(s) or licensor are credited and that the original publication in this journal is cited, in accordance with accepted academic practice. No use, distribution or reproduction is permitted which does not comply with these terms. 